\title{
Community-wide effects of protection reveal insights into marine protected area effectiveness for reef fish
}

\author{
E. R. Heyns-Veale ${ }^{1,2, *}$, A. T. F. Bernard ${ }^{2,3}$, A. Götz ${ }^{1,4}$, B. Q. Mann ${ }^{5}$, J. Q. Maggs ${ }^{5}$, \\ M. K. S. Smith \\ ${ }^{1}$ South African Environmental Observation Network (SAEON), Elwandle Node, NMMU Ocean Sciences Campus, \\ 4 Gomery Avenue, Summerstrand, Port Elizabeth, 6031, South Africa \\ ${ }^{2}$ South African Institute for Aquatic Biodiversity (SAIAB), Somerset Street, Makhanda 6140, South Africa \\ ${ }^{3}$ Department of Zoology and Entomology, Rhodes University, Makhanda 6140, South Africa \\ ${ }^{4}$ Zoology Department, Nelson Mandela University, Port Elizabeth 6031, South Africa \\ ${ }^{5}$ Oceanographic Research Institute, PO Box 10712, Marine Parade, Durban 4056, South Africa \\ ${ }^{6}$ Rondevlei Scientific Services, South African National Parks, Sedgefield 6573, South Africa
}

\begin{abstract}
Marine protected areas (MPAs) are not designed the same, nor are they equally effective. Efficacy of MPAs is frequently gauged by measuring the direct ecological responses of fish communities. However measuring the indirect, or knock-on effects from protection can provide additional insight into MPA effectiveness at the community level. Here we applied traitbased and community analyses to investigate MPA effectiveness by evaluating both direct and indirect effects of protection on fish assemblages using baited remote underwater stereo-video data from inside and outside 5 no-take MPAs along the South African coastline. The trait-based analyses indicated the presence of a significant overall direct effect (increased abundance of mature individuals targeted by fisheries) and indirect effects (reduction of the abundance of species not targeted by fisheries) inside MPAs, and highlighted that fish maturity is an essential trait to incorporate when assessing direct effects of protection. However, investigation of the species data of the individual MPAs showed positive reserve effects at the community level (both direct and indirect effects) in only 3 MPAs. For the most part these results conform with current theories on the factors that contribute to MPA effectiveness. Yet, one old, large and isolated no-take MPA showed no direct effects of protection, which is attributed to the lack of adequate offshore reef habitat throughout this MPA. While these results support the value of MPAs as ecosystem management tools, they highlight the need for appropriate site selection when designing MPAs.
\end{abstract}

KEY WORDS: MPA effectiveness · NEOLI - Stereo-BRUVs · Functional entities · Life-stage · Ecological isolation

\section{INTRODUCTION}

Due to rapidly changing ecosystems, the urgency to establish effective marine protected areas (MPAs) is now greater than ever (Edgar 2017). Effective MPAs increase diversity, local abundance and biomass and support the recovery of depleted stocks

\footnotetext{
${ }^{*}$ Corresponding author: elodieheyns@gmail.com
}

within their boundaries (Gell \& Roberts 2003, Worm et al. 2006, Lester et al. 2009). However, many MPAs are ineffective and fail to achieve biodiversity and fisheries management goals (Edgar et al. 2014, Gill et al. 2017). Therefore, it is not surprising that MPA implementation, especially as a fisheries management tool, has been under much scrutiny (Agardy et al.

() The authors 2019. Open Access under Creative Commons by Attribution Licence. Use, distribution and reproduction are unrestricted. Authors and original publication must be credited. 
2003, Hilborn et al. 2004, Jones 2007, Rice et al. 2012). Nonetheless, MPAs are still a popular management tool which aims to conserve biodiversity and mitigate the anthropogenic impacts associated with fishing (Pikitch et al. 2004, Fletcher et al. 2010). To ensure MPAs are effective and beneficial, more reliable primary research and in-depth synthesis of current knowledge is needed to provide a solid basis for management and policy implementation (Halpern 2014, Woodcock et al. 2017).

Fishing typically targets larger-bodied species and individuals, due to both fishing regulations and angler/consumer preference (Pauly et al. 2002, Gwinn et al. 2015). Fishing thus reduces the abundance and biomass of target species, truncates size distributions and reduces spawner biomass of affected populations (Jennings \& Kaiser 1998, Myers \& Worm 2003). Recoveries of spawner biomass and exploited populations are therefore considered direct effects of protection. Such direct effects are well documented (Cowley et al. 2002, Halpern 2003, Russ \& Alcala 2003, Aburto-Oropeza et al. 2011) and commonly identified by comparing target fish abundance and biomass between protected and exploited sites (Halpern 2003, Micheli et al. 2004, Willis \& Millar 2005, Maggs et al. 2013, Soler et al. 2015). Larger fish species are usually predators and thus important in the regulation of prey populations (Jennings \& Kaiser 1998), or can be superior competitors that affect species interactions. Selective removal of larger, higher trophic level species can therefore lead to alterations in the structure of a fish community (Babcock et al. 1999, Jennings et al. 1999, Pinnegar et al. 2000) due to ecological release, from both predators (prey release) and interspecific competition (Chase et al. 2002). Such community-wide changes are considered indirect effects of fishing, and are expected to manifest in higher abundances of species that are prey, occupy lower trophic levels, are less competitive, or are less desirable from an angling perspective (non-target species). In the context of MPA effectiveness, indirect or community-wide effects of protection will only be detected once target populations have recovered to the point where they influence the abundance of non-target species (Babcock et al. 2010). Consequently, we can gauge the efficacy of an MPA by monitoring non-target species abundances in concert with the biomass of target species. As such, investigation of both direct and indirect effects can provide a more complete assessment of MPA effectiveness, and give greater insight into the factors that maximise their conservation value. Importantly, although indirect effects might in certain instances be an undesirable outcome, they nonetheless represent the restoration to the natural state, and should be viewed as indicative of an MPA which managed to restore and maintain ecosystem functioning.

The direction and strength of direct and indirect effects arising from MPAs can be attributed to ecological processes and/or management criteria. From an ecological perspective, the species diversity and level of omnivory in an ecosystem, habitat complexity (Salomon et al. 2010) and the trophic groups considered (Babcock et al. 2010) are all thought to affect the extent of indirect effects from fishing. From a management and planning point of view, reserve characteristics such as no-take zonation, enforcement, old age, large size and ecological isolation (the NEOLI criteria, see Edgar et al. 2014), as well as governance, buffer size and budget, influence MPA effectiveness (Edgar et al. 2014, Gill et al. 2017, Woodcock et al. 2017).

To obtain a more holistic understanding of MPA effectiveness, standardised and comparable data from inside and outside multiple replicate MPAs need to be collected. However, because MPAs are typically widely spaced along a coastline, environmental filtering by changes in conditions, competitive exclusion and stochastic processes can lead to high turnover in fish assemblage structure (Lamanna et al. 2014). Consequently, such fish communities are not often comparable, as there is no broad-scale consistency in the species, making it difficult to identify general patterns (Keddy 1992, Hockey \& Branch 1997, Day \& Roff 2000). Functional trait-based analysis is a possible solution, as species from all locations are grouped according to a set of generic functional traits, thereby removing local variation in species identity and facilitating broad-scale analyses (Weiher \& Keddy 1995, Violle et al. 2014). In addition, trait-based analyses can provide insights into the biological traits that are most sensitive to direct or indirect effects of protection (Thrush \& Dayton 2010, Mouillot et al. 2013, 2014, Coleman et al. 2015, Villéger et al. 2017).

Here, we quantified the direct and indirect effects of protection by examining the abundance and biomass of target and non-target fish species collected between 2013 and 2016, inside and outside 5 no-take MPAs from the warm-temperate and subtropical ecoregions of southern Africa. We first established if direct effects of protection were evident before investigating any secondary or indirect effects. Direct effects were expected to manifest as a significant increase in the average biomass of target species inside MPAs due to absence of selective targeting of larger individuals by fishing, and were considered a positive 
reserve effect at the resource level (target species). In contrast, indirect effects were expected to manifest as a significant decrease in the abundance of non-target species inside MPAs due to either predation or competition from the recovered populations of target species (Götz et al. 2009). The presence of both direct and indirect effects of protection was considered to be a strong positive reserve effect at the community level (i.e. predators and highly competitive species have recovered to the point that they significantly affect the abundances of prey or interspecific competitors). Analyses were based on multivariate response data. Due to differences in fish species sampled from different MPAs, we first took a functional trait-based approach to establish if there was an overall effect of protection on target species and non-target species. Next, we investigated the protection effect at each MPA using species data.

\section{MATERIALS AND METHODS}

\subsection{Study region}

Data were collected from inside and outside 5 MPAs from the south-west to central north-east coast of South Africa (Fig. 1). Moving west to east, the 5 MPAs investigated were De Hoop, Tsitsikamma National Park, Bird Island, Amathole, and Pondoland (Fig. 1). Within the study region, there is a gradual increase in sea water temperature from the west to the east, which is associated with a similarly gradual turnover in species composition along the coastline (Table 1). The data set thus spans a diverse array of ecosystems in the warm-temperate ecoregion of southern Africa, with Pondoland being the only subtropical representative (Fig. 1; see Sink et al. 2012).

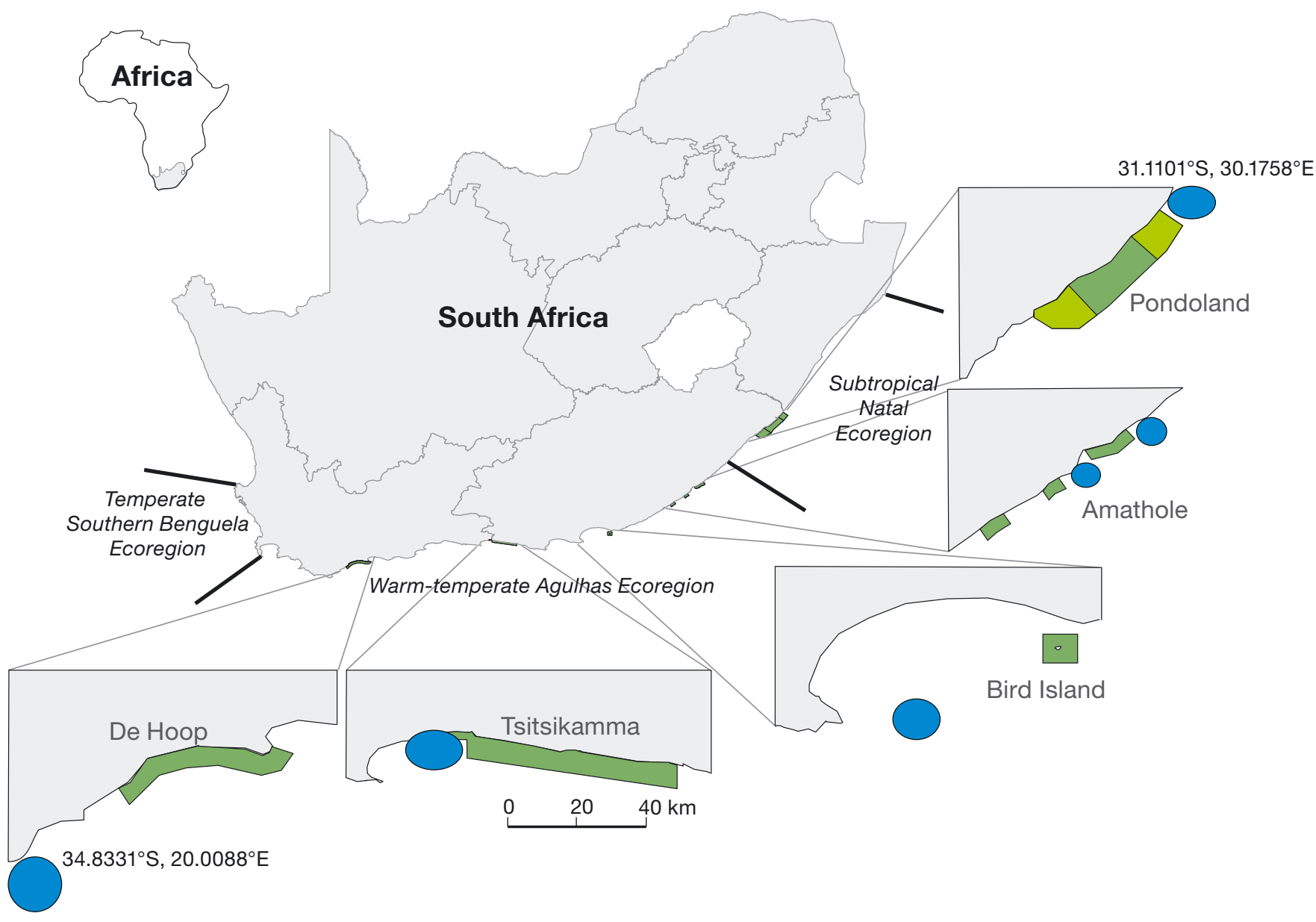

Fig. 1. Locations of the 5 studied marine protected areas (MPAs) along the south-east coast of South Africa. Dark lines demarcate the different marine ecoregions (in italics) along the South African coastline. Green represent no-take zones within the studied MPAs and blue circles represent the fished sites 


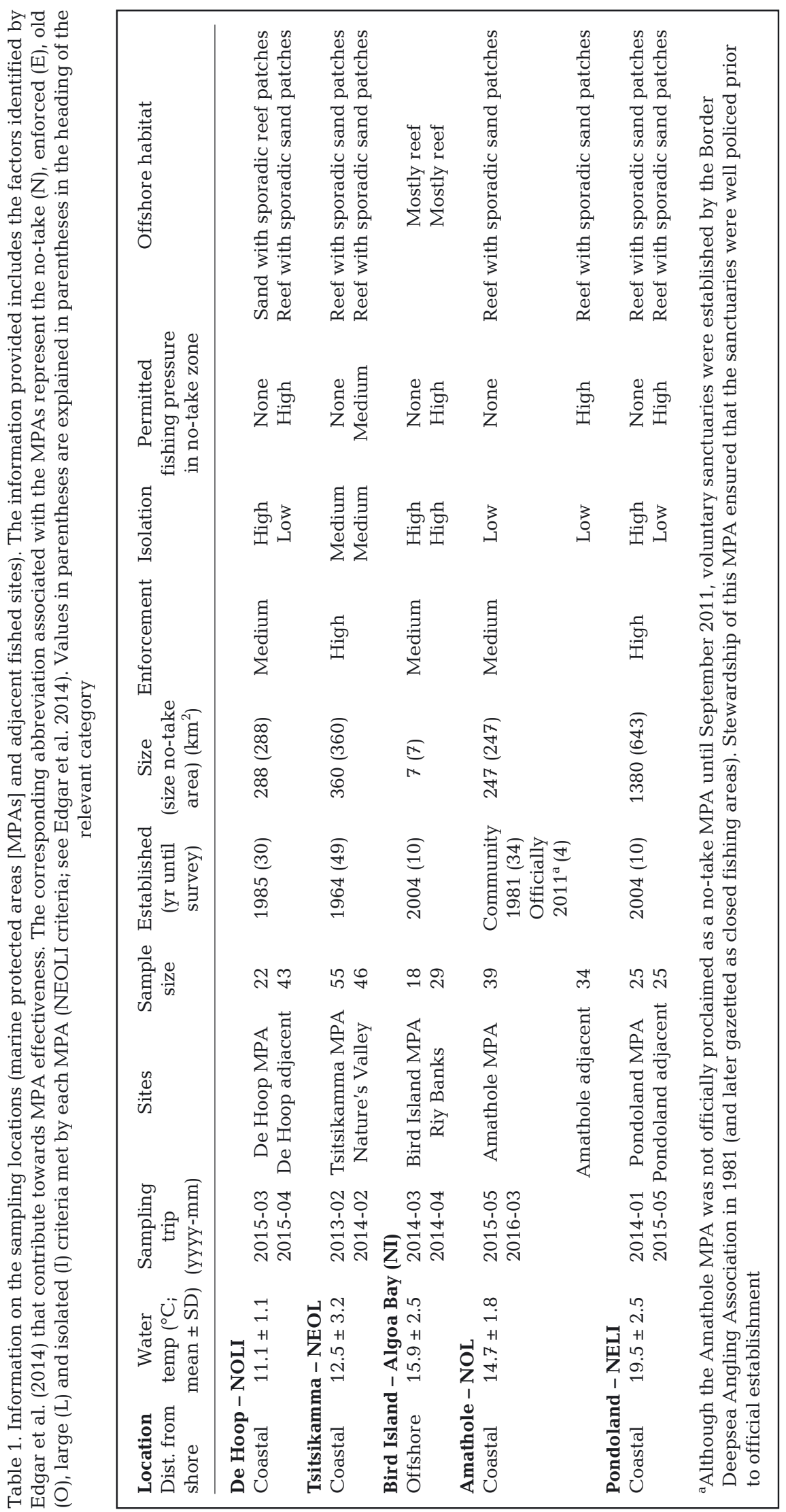

\subsection{Sampling strategy and technique}

At each of the 5 locations (which herein refers to both the MPA and adjacent fished site) reef fish assemblage data were collected within the MPA and at nearby unprotected zones, where fishing is known to occur (Table 1). Sampling took place from February 2013 to March 2016. All data collected within the MPAs were collected from the no-take zones, where no extractive activity is allowed. Samples of the reef fish assemblages were collected from reefs between 10 and $60 \mathrm{~m}$ depth at randomly selected sampling stations with a minimum distance of $300 \mathrm{~m}$ between adjacent stations. The minimum separation of $300 \mathrm{~m}$ was selected to avoid spatial autocorrelation and the confounding effects of the bait plume (Taylor et al. 2013).

Reef fish assemblages were sampled with baited remote underwater stereo-video systems (stereo-BRUVs), which constitute a standardised fisheries-independent method that allows for the estimation of relative abundances and accurate size measurements (Harvey \& Shortis 1996, Harvey et al. 2001, Watson et al. 2005). Stereo-BRUVs were employed in this study as they are currently the only non-destructive method that is able to sample the depth range of the MPAs, including the depths at which fishing predominantly occurs in South Africa. At each sampling station, a single stereo-BRUVs was deployed from a boat and left on the seabed to record for a 60 min period (Watson et al. 2005, Langlois et al. 2012a,b, Bernard et al. 2014). The stereo-BRUVs design was simi- 
lar to that described in Bernard et al. (2014) and consisted of a stainless steel frame with 2 high-definition digital cameras mounted $70 \mathrm{~cm}$ apart converging inwards at an angle of $8^{\circ}$, baited with approximately $800 \mathrm{~g}$ of crushed sardine Sardinops sagax.

\subsection{Video analysis}

Video samples were processed in EventMeasure (Stereo) software (www.seagis.com.au). Abundance was estimated as the maximum number of individuals of a species recorded in one video frame over the 60 min analysis period (MaxN; Willis \& Babcock 2000). Where possible, the fork or total length, as appropriate for the species, was measured for each fish counted in the MaxN frame. Biomass was estimated using the Bayesian length-weight relationships obtained from FishBase (Froese \& Pauly 2014) and averaged for each species per stereo-BRUVs sample. To ensure accurate length measurements were obtained in EventMeasure, camera sets were calibrated before and after each field trip with the CAL v1.32 software (www.seagis.com.au), following Harvey \& Shortis $(1996,1998)$.

\subsection{Target and non-target fish species}

This study focussed on 2 main groups of reef fish: those reef fish species considered to be primary targets of the local commercial and recreational fisheries (i.e. those that are preferentially captured due to angler preferences and economic value) and fish species that are not targeted (non-targets) and typically not kept (Table S1 in the Supplement at www. int-res.com/articles/suppl/m620p099_supp.pdf). Species were categorised according to information obtained from Mann (2013) and expert opinion (Table S1). Primary target species were included, as they are expected to demonstrate the strongest effect of fishing, and they are often superior competitors. Non-target species were included as variations in their populations can be assumed to be independent of the direct effects of fishing. Fish species of minor importance to fisheries (i.e. those that are less desirable, but kept when caught for bait or subsistence) were excluded from the analyses as their populations are likely to be influenced by both fishing pressure and top-down effects of biotic interactions. Analyses also excluded pelagic or migratory species whose movement behaviour makes them susceptible to fishing outside of MPAs.

\subsection{Trait classification}

The gradual turnover of fish species, moving from the colder southwest coast to the warmer northeast coast of South Africa, resulted in unique fish assemblages at each location (especially apparent between Pondoland and the locations to the west). Consequently, a trait-based approach was taken to test the overall hypothesis that fishing affected the functional structure of the fish community. The traits were based on Mouillot et al. (2014) with slight modifications to suit our specific questions. Our traits included maximum body size, diet preference, preferred position in the water column, mobility and shoaling behaviour, which were applied at the species level; and life-stage (an estimate of individual maturity, using the length measurements obtained from the stereo-BRUVs; Table S2). These traits were selected as they represent functional characteristics of fish species that influence biotic interactions and influence their vulnerability to fishing pressures. The trait-based analyses were in 2 forms; the first focussed only on species-level functional traits, where fish were grouped to create 'species level functional entities' (SFEs), and the second included the individuallevel functional trait of life-stage together with the species-level functional traits, where fish were grouped to create 'individual and species level functional entities' (ISFEs; Table S2).

Life-stage was assigned by taking the individual size measurement of each fish sample and classifying it as either adult or juvenile based on the size at $50 \%$ maturity, which was obtained from FishBase (Froese \& Pauly 2014). Where no published maturity data were available, the size at $50 \%$ maturity was predicted based on the relationship between maturity and maximum attainable size of other species in the same fish family (Table S3; Figs. S1 \& S2 in the Supplement). Where there were insufficient data to model the relationship between maturity and maximum attainable size for a specific fish family, the species were assigned the average proportion of size at maturity/maximum size for their type (bony fish or elasmobranchs).

\subsection{Explanatory variables of secondary interest}

To differentiate between habitat and MPA effects we included quantitative and categorical explanatory variables to control for variation in the data, which were not attributable to variables of primary interest (Miller \& Russ 2014). The explanatory vari- 
ables recorded for each stereo-BRUVs sample were field of view (visibility and percent visible water column), temperature $\left({ }^{\circ} \mathrm{C}\right)$, depth $(\mathrm{m})$ and bottom type. Visibility (m) for each stereo-BRUVs sample was estimated in EventMeasure by creating a 3D point at the furthest distance at which an object could easily be identified. Percent visible water column was calculated in the Vidana software (Hedley 2003) by quantifying the amount of visible water column in relation to visible reef. Average water temperature for the duration of each stereo-BRUVs deployment was obtained from temperature loggers (HOBO Pro v2, Onset) attached to the stereo-BRUVs systems. Sample depth was recorded from the boat's echo sounder, and bottom types were classified into one of 5 categories from images of the seafloor taken from each stereo-BRUVs samples. The 5 bottom types were sand-inundated reef (reef covered in a thin layer of sand, with small patches of reef or erect macrobenthos breaking through), patch-reef low (mosaic of sand and reef, visible reef varying by $<1 \mathrm{~m}$ in height), patch-reef high (mosaic of sand and reef, visible reef varying by $>1 \mathrm{~m}$ in height), reef low (100\% reef varying by $<1 \mathrm{~m}$ in height) and reef high (100\% reef varying by $>1 \mathrm{~m}$ in height). Samples with $100 \%$ sand were excluded from the analyses.

\subsection{Statistical analyses}

Multivariate (permutational multivariate analysis of variance; PERMANOVA) and univariate (permutational analysis of variance; permutational ANOVA) analyses were conducted in PRIMER v7 with PERMANOVA+ add-on (Anderson et al. 2008, Clarke \& Gorley 2015) and based on 3 model designs. (1) The first model design was to test the hypothesis that protection affects trait combinations (SFEs and ISFEs) of the fish assemblages, with 'location' (De Hoop, Tsitsikamma, Bird Island, Amathole, Pondoland) as a random factor and 'status' (protected or exploited) as a fixed factor, with an interaction between location and status. (2) The second model design tested the impact of protection on fish at the species-level in terms of abundance and biomass data by considering the main effects and interaction effect between 'status' and 'location'. (3) The third model tested if the univariate summed MaxN and the average biomass differed between exploited and protected sites separately for each location thus only including 'status' as a fixed factor.

To account for variability in the data due to differences in sample-specific environmental variables, the estimated covariates (e.g. visibility, depth) were added before the terms (e.g. location, status) in the models. Thus all models were first fitted with the continuous covariates in the following order: 'visibility', 'percent water column', 'temperature', 'depth' and the categorical covariate 'bottom type' (random effect). These covariates were then followed by 'location', (model 1: random effect, model 2: fixed effect) and 'status' (fixed effect), in a sequential PERMANOVA. All analyses were done separately for the target and non-target species to help determine the direction of change for each of the groups. Because of the unbalanced nature of the sampling design, analysis was based on type I sum of squares using 9999 permutations under a reduced model (Anderson et al. 2005, 2008). Pairwise analyses were conducted where significant results were observed.

Trait-based analyses were performed on a fourthroot transformed, adjusted Bray-Curtis resemblance measure (to accommodate samples where no fish were recorded) and univariate analysis on untransformed adjusted Euclidean distances. Analysis of species data (abundance and average biomass) were based on the adjusted Modified Gower log base 5 distance measure. Modified Gower accounts for highly abundant species, as it places greater emphasis on the compositional change of a community rather than actual MaxN or average biomass values (Anderson et al. 2006). Here we also applied Modified Gower to the biomass data, since relative abundances of organisms measured by continuous biomass values behave, statistically, in a very similar way to relative abundances recorded as integer counts (variance is a function of the mean, over-dispersed, bounded at zero, right-skewed). When Modified Gower is applied to biomass values, the resulting dissimilarity value is interpreted as the average log-difference in biomass per species (Anderson et al. 2006). We chose to use a log base of 5 , so that one unit in Modified Gower space corresponds to a 5-fold difference in biomass. The species abundance and biomass data of each location (MPA and adjacent fished area) were visualised in PRIMER v7 using metric multidimensional scaling (mMDS), which compared to the more traditional principal coordinate analysis, is more robust and provides greater reduction of dimensionality to visualise important patterns (Clarke \& Gorley 2015). Finally, similarity percentages (SIMPER) were estimated to identify the trait combinations / fish species that together contributed to $70 \%$ of the dissimilarity between exploited and MPA sites at each location (Clarke \& Gorley 2015) 


\section{RESULTS}

\subsection{Trait-based analyses}

\subsubsection{Abundance}

(species level functional entities; SFEs)

According to the trait-based analyses, no overall effect of protection was observed in the abundances of the SFEs within the target species group (pseudo-
$F_{1}=1.12 ; \mathrm{p}=0.404 ;$ Table S4a). However, there was a significant interaction effect between 'location' and 'status' (pseudo- $F_{4}=8.31 ; \mathrm{p}<0.001$; Table S4a), with the pairwise analyses indicating that 'status' (protection) significantly affected the SFEs of the target species at all locations (Table S5a), but that the direction of impact was inconsistent. This was also illustrated in the SIMPER results, where the effect of protection on the average abundances of the target SFEs varied between locations and different SFE groups (Fig. 2a;

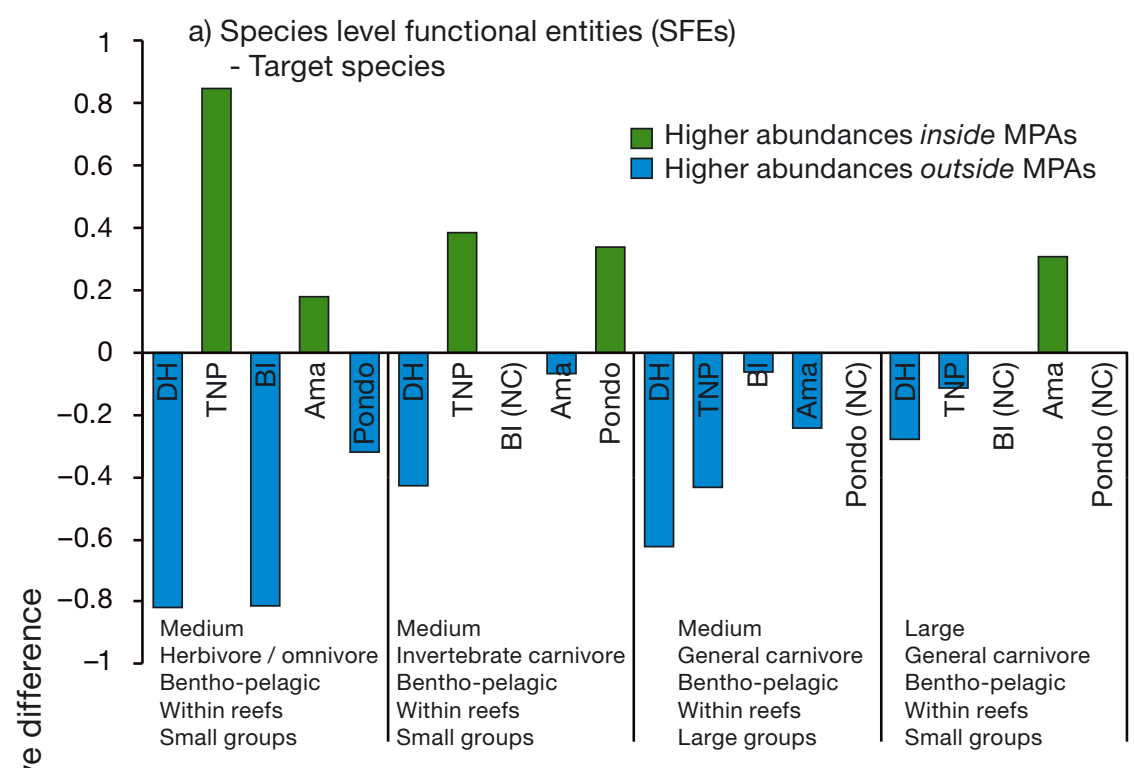

c) Individual and species level functional entites (ISFEs)
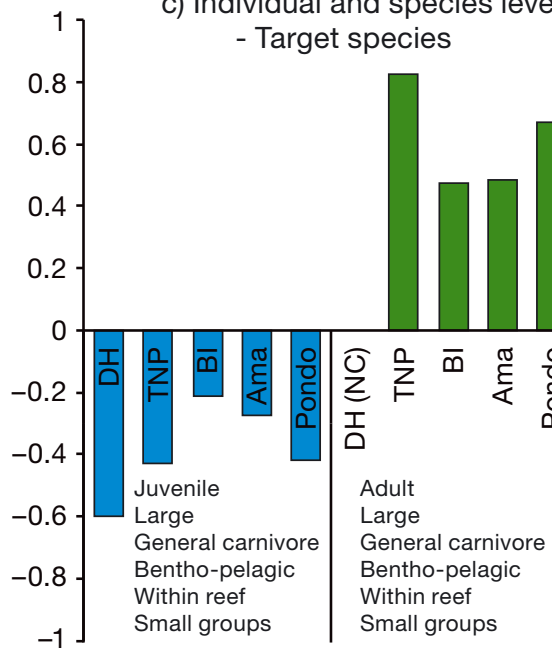
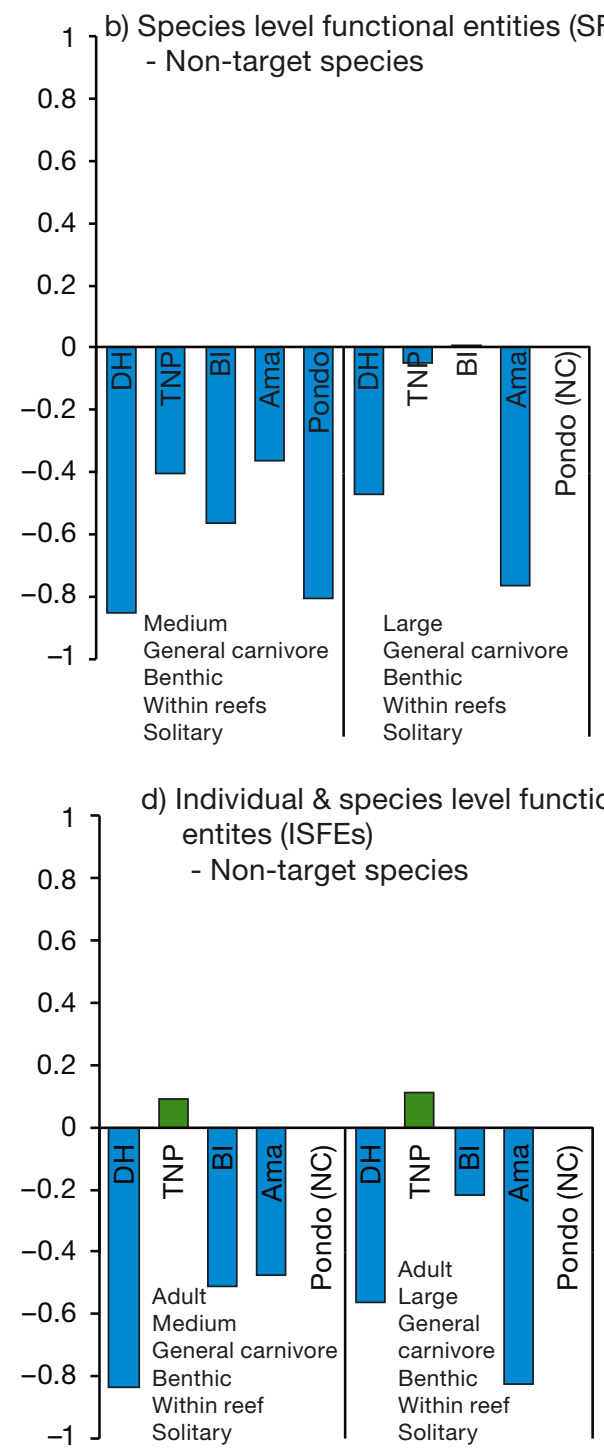

Fig. 2. Results from the similarity percentages (SIMPER) of the species level functional entities (SFEs; abundance) of (a) target species and (b) non-target species. Individual and species-level functional entities (ISFEs; length) of (c) target species and (d) non-target species. Data are the average abundances calculated from the fourth root transformed Bray-Curtis resemblances. The SIMPER results are expressed as the relative difference in abundance between protected and exploited sites where zero $=$ no difference and 1 or $-1=100 \%$ different. Functional entities with higher values inside the marine protected area (MPA) are plotted on the positive scale (green) and functional entities with higher values outside the MPA on the negative scale (blue). DH: De Hoop, TNP: Tsitsikamma, BI: Bird Island, Ama: Amathole, Pondo: Pondoland. $(\mathrm{NC})=$ no contribution, indicating that the functional entity did not contribute to the $70 \%$ dissimilarity between protected and exploited sites at the specific location.

For full SIMPER results and species represented by each functional entity see Tables S6 \& S8 in the Supplement 
Table S6). The abundances of non-target SFEs was significantly affected by protection (pseudo- $F_{1}=$ 12.15; $\mathrm{p}=0.014$; Table S4b), with pairwise analyses indicating a significant effect at all locations, except for Bird Island (Table S5b). In contrast to the target species, the direction of impact was consistent for all functional entities of the non-target groups, with higher average abundances at exploited compared to protected locations (Fig. 2b; Table S6).

\subsubsection{Length (individual and species level functional entities; ISFEs)}

In contrast to the results from the SFEs, which did not take into account the individual size of the fish observed, protection significantly affected the ISFEs within the target group (pseudo- $F_{1}=4.2 ; \mathrm{p}=0.027$; Table S7a), with pairwise analyses indicating a significant protection effect at all locations, Table S5c). The SIMPER results of the target group revealed a fairly consistent pattern for the ISFEs, with higher average abundances of adult fishes in protected compared to exploited locations (Fig. 2c; Table S8a). However, while no main effect of protection was observed for the non-target group (pseudo- $F_{1}=4.48$; $\mathrm{p}=0.062$; Table $\mathrm{S} 7 \mathrm{~b}$ ), the interaction revealed a significant effect of protection at De Hoop, Tsitsikamma and Pondoland (Table S5d). For the non-target ISFEs, adult fishes were also most consistently affected, with higher average abundances outside most of the MPAs, except Tsitsikamma (Fig. 2d; Table S8b).

\subsection{Multivariate analysis on species data}

\subsubsection{Target species}

Examination of the multivariate species data revealed that the abundance and biomass of target species assemblages were significantly affected by protection at all locations (abundance: pseudo- $F_{1}=9.1$; $\mathrm{p}<0.001$; biomass: pseudo- $F_{1}=6.84 ; \mathrm{p}<0.001$; Tables S9a \& S10a). Although pairwise analyses supported this finding (Table S11a,c), the mMDS, SIMPER and univariate outputs revealed that the direction of change differed among locations (Figs. 3-7a,b).

\subsubsection{Non-target species}

Similar to the target species, the abundance and biomass of non-target species assemblages were significantly influenced by protection (abundance: pseudo- $F_{1}=9.1 ; \mathrm{p}<0.001$; biomass: pseudo- $F_{1}=6.84$; $\mathrm{p}<0.001$; Tables S9b \& S10b). Pairwise comparisons indicated that protection significantly affected the abundance of non-targets at all locations. On the other hand, there was no effect of protection on the biomass of non-target species at the Amathole and Pondoland locations (Table S11d).

\subsubsection{De Hoop Marine Protected Area}

Fish assemblages (abundance and biomass) of target and non-target species differed between MPA and fished areas (Fig. 3), with higher abundance and biomass of reef-associated species outside the MPA, in comparison to inside the MPA (Fig. 3). The exception was Mustelus mustelus, for which higher abundance and biomass estimates were observed inside the MPA, in comparison to outside (Fig. 3e,f). The pattern observed for the non-target species at the De Hoop MPA was similar to the target species with higher abundance and biomass values outside the MPA (Fig. 3c-f). Univariate analyses of the summed MaxN and average biomass revealed no difference between the exploited and protected sites for any of the response variables considered (target abundance: pseudo- $F_{1}=6.81 ; \mathrm{p}=0.086$, target biomass: pseudo- $F_{1}=1.4 ; \mathrm{p}=0.337$, non-target abundance: pseudo- $F_{1}=5.2 ; \mathrm{p}=0.091$ and non-target biomass: pseudo- $F_{1}=5.07 ; \mathrm{p}=0.12$ ).

\subsubsection{Tsitsikamma National Park Marine Protected Area}

The target and non-target fish assemblages at the Tsitsikamma MPA differed significantly in terms of abundance and biomass (Fig. 4a-d). Results from the mMDS and the SIMPER analysis suggest that both abundance and biomass values of the target species were higher inside compared to outside the MPA (Fig. 4a,b,e,f). However, not all target species were recorded at higher abundances inside the MPA, with Argyrozona argyrozona, Pterogymnus laniarius and Rhabdosargus globiceps being more abundant at exploited sites (Fig. 4e). This variable pattern in the abundance of target species was supported by the absence of a significant protection effect in the univariate analysis of summed target species MaxN (pseudo- $F_{1}=0.22 ; \mathrm{p}=0.695$ ). Higher average biomass values (mean $\pm \mathrm{SD}$ ) were recorded inside the 
a) Target species (abundance)

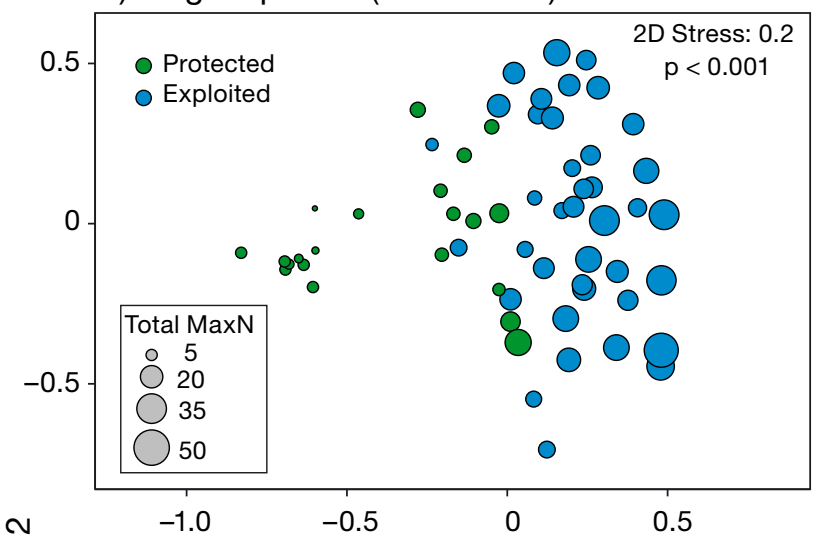

$N$
$\stackrel{D}{\Sigma}$

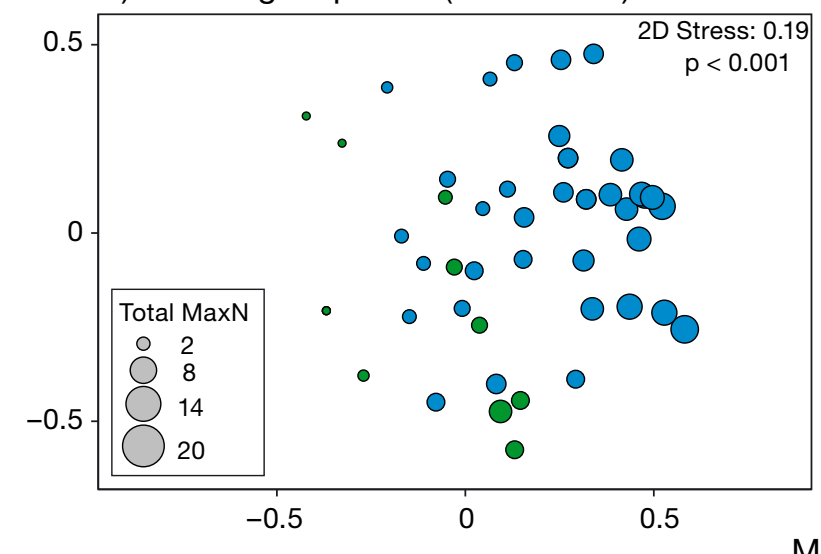

\section{De Hoop Marine Protected Area}

b) Target species (biomass)

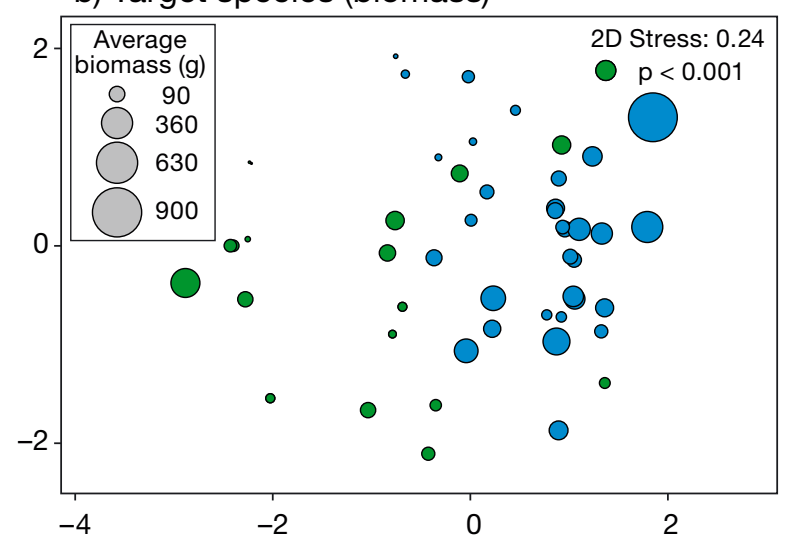

d) Non-target species (biomass)

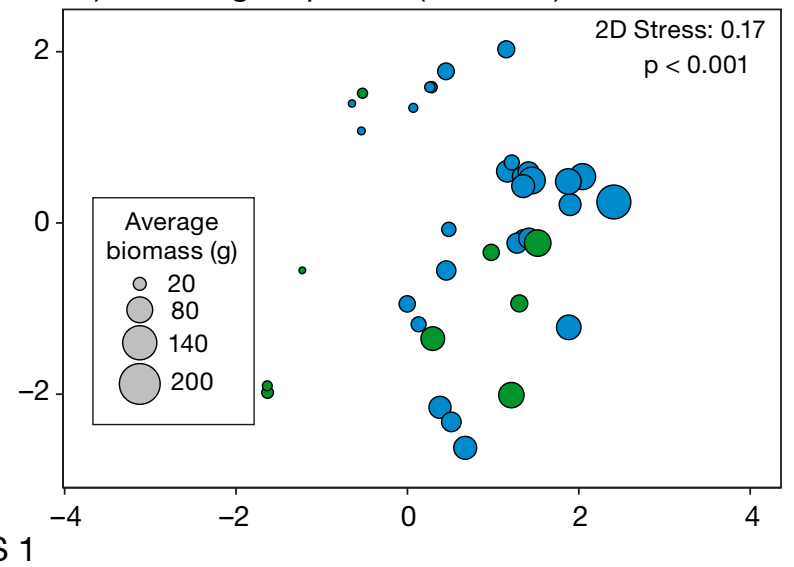

e) SIMPER: abundance

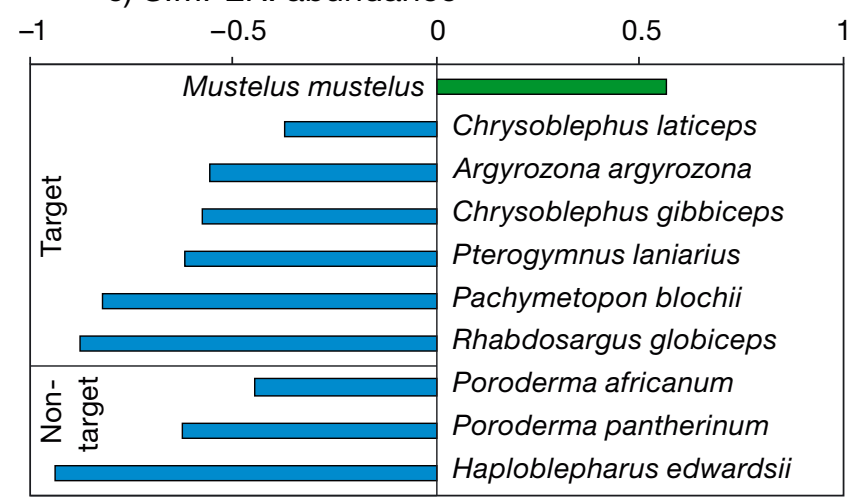

f) SIMPER: biomass

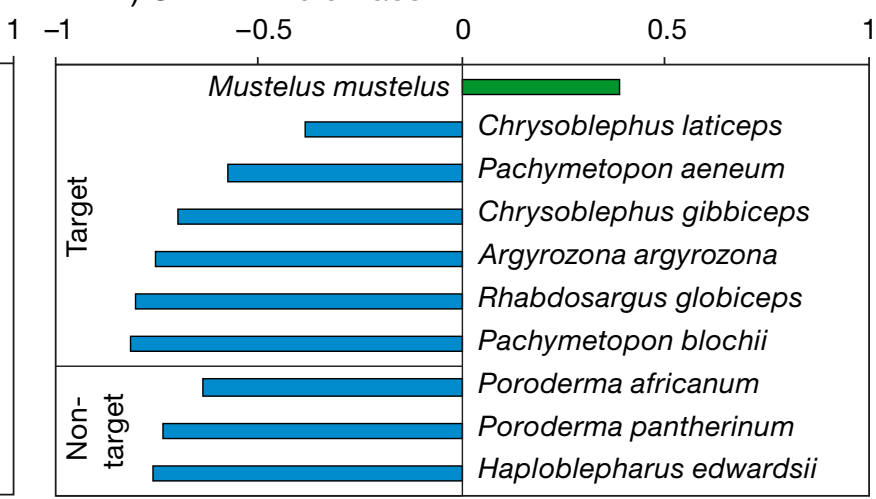

\section{Relative difference}

Fig. 3. Metric multi-dimensional scaling (MDS) of the abundance (MaxN) and biomass (average) values recorded for (a,b) target and $(\mathrm{c}, \mathrm{d})$ non-target species at the De Hoop Marine Protected Area. Bubble sizes represent the total MaxN of each stereo-BRUVs sample for the abundance plots, and averaged biomass for the biomass plots. (e,f) Bar graphs show the similarity percentage (SIMPER) results of the average abundance and biomass calculated from fourth root transformed Bray-Curtis resemblances. The SIMPER results are expressed as the relative difference in abundance/biomass between protected and exploited sites where zero $=$ no difference and 1 or $-1=100 \%$ different. Fish with higher values inside the MPA are plotted on the positive scale (green) and fish with higher values outside the MPA on the negative scale (blue). p-values represent pairwise results (Table S11) 
Tsitsikamma National Park Marine Protected Area

a) Target species (abundance)

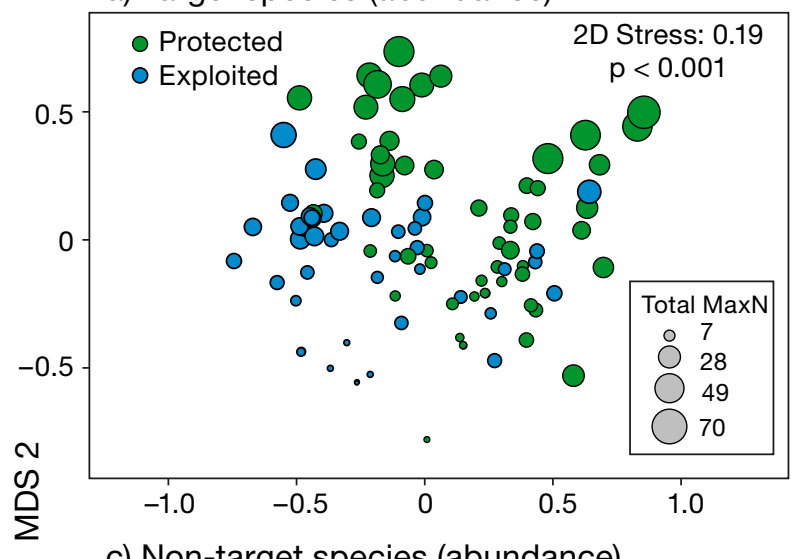

c) Non-target species (abundance)

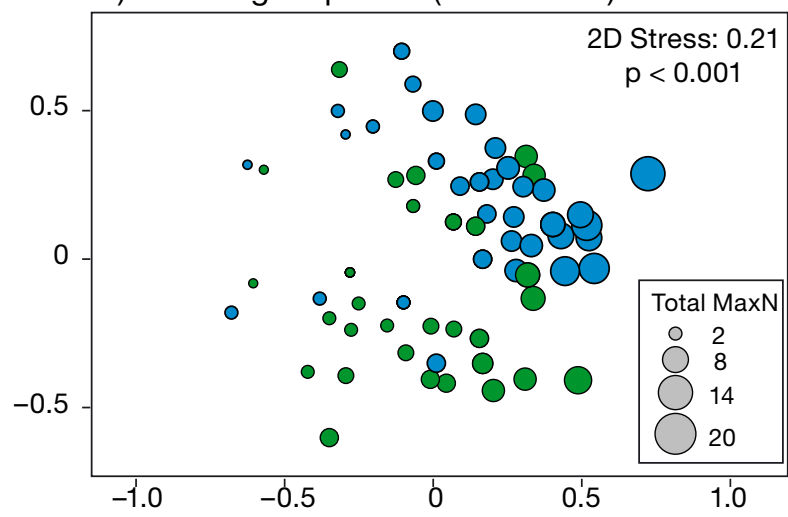

MDS 1 b) Target species (biomass)

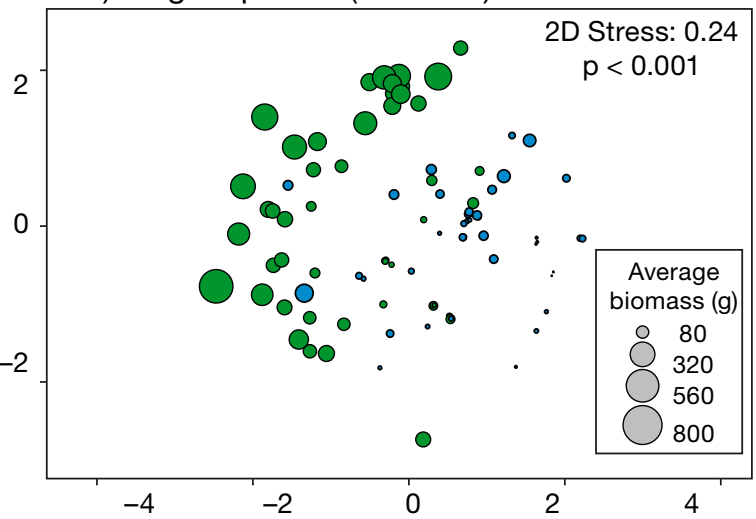

d) Non-target species (biomass)

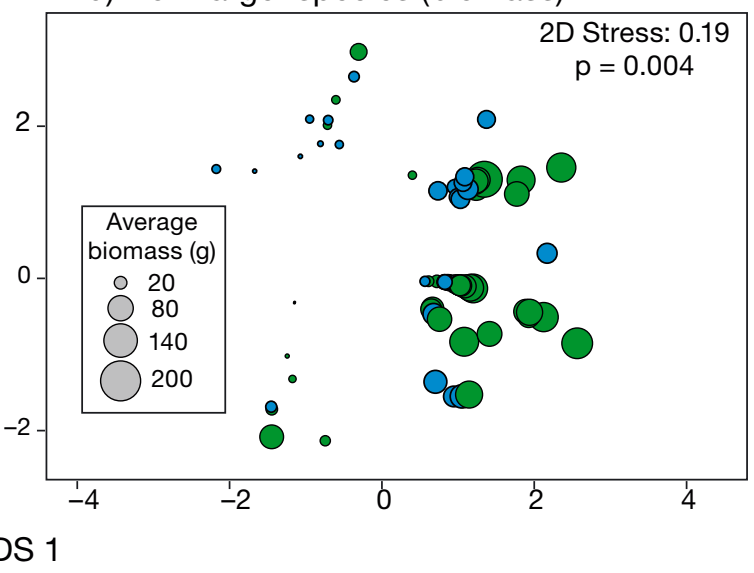

f) SIMPER: biomass

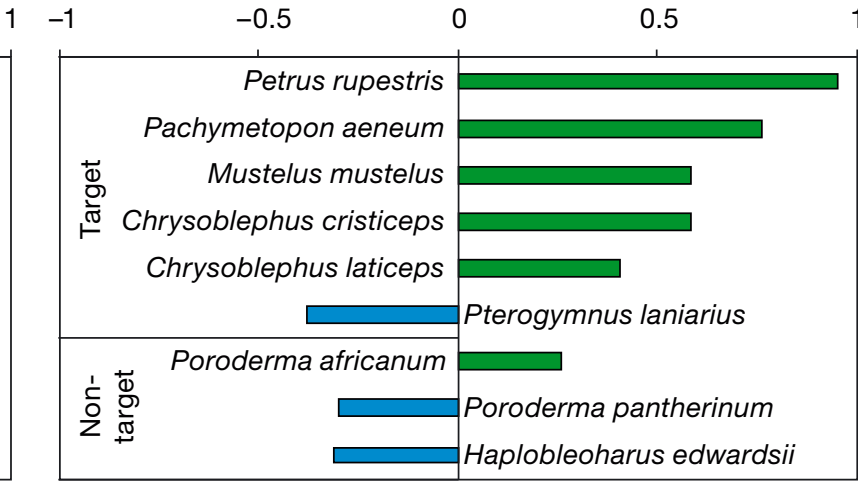

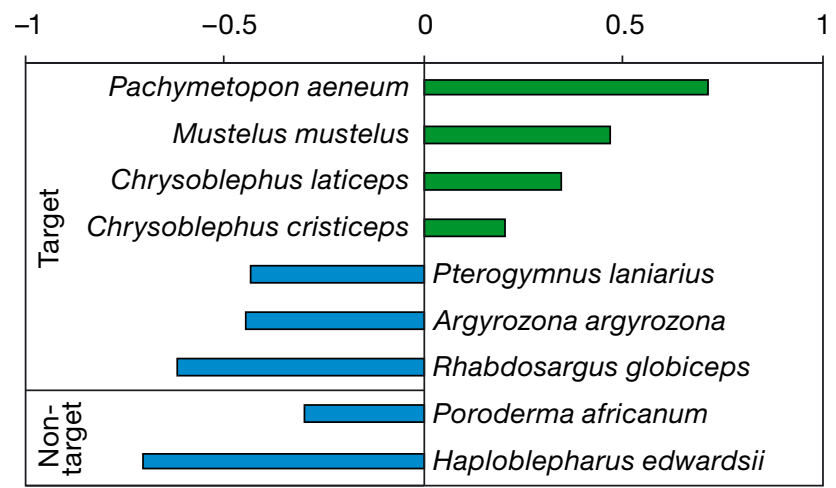

Relative difference

Fig. 4. As in Fig. 3, but for the Tsitsikamma National Park Marine Protected Area

Tsitsikamma MPA for target species (protected: $175.2 \pm 153.6$; exploited: $36.6 \pm 40.4$ gi pseudo $-F_{1}=$ $48.7 ; \mathrm{p}=0.003$; Fig. $4 \mathrm{~b}$ ) and the results from the SIMPER analyses revealed that the biomass of all the highest contributing species, except $P$. laniarius, were higher inside the MPA compared to outside. The abundances of non-target species were signifi- cantly higher outside the Tsitsikamma MPA (mMDS; Fig. 4c) as indicated by the SIMPER results (Fig. 4e) and the univariate analysis of the summed MaxN (protected: $2.9 \pm 2.1$; exploited: $4.7 \pm 3.1$; pseudo- $F_{1}=$ $108.58 ; \mathrm{p}<0.001)$. There was no effect of protection on the average biomass of non-target species (pseudo- $F_{1}=1.47 ; \mathrm{p}=0.286 ;$ Fig. $4 \mathrm{~d}, \mathrm{f}$ ). 


\subsubsection{Bird Island Marine Protected Area}

Multivariate analyses of the target and non-target abundance and biomass data revealed a significant protection effect on the Bird Island fish assemblages (Fig. 5a-d). Although protection affected the assemblage structure of the target species abundances, no obvious difference was evident in the mMDS or univariate analysis (Fig. $5 a_{;}$pseudo- $F_{1}=2.43$; $p=0.225$ ). Yet the SIMPER analysis suggested higher abundances of most target species inside the Bird Island MPA (Fig. 5e). Target species had higher average biomass inside the Bird Island MPA (mean \pm SD; Fig. 5b,f; protected: $195.6 \pm 127.6$; exploited: $121.1 \pm$ $57.5 \mathrm{~g}$; pseudo- $F_{1}=28.8 ; \mathrm{p}=0.021$ ). Abundances of non-target species tended to be higher outside the Bird Island MPA (Fig. 5c,e), which was supported by the significant protection effect in the univariate analysis (protected: $2.6 \pm 1.7$; exploited: $4.3 \pm 2.5$; pseudo- $\left.F_{1}=34.61 ; \mathrm{p}=0.014\right)$. The SIMPER and the mMDS analysis run on the biomass data of non-target species showed higher overall biomass outside the Bird Island MPA, however, this pattern was not supported by the univariate analysis (Fig. 5d,f; pseudo- $F_{1}=1.12 ; \mathrm{p}=0.377$ ).

\subsubsection{Amathole Marine Protected Area}

Multivariate analyses of the target species abundance and biomass data indicated significantly different fish assemblages in the exploited compared to protected sites of the Amathole MPA (Fig. 6a,b). The mMDS output of the abundance values of the target species suggests similar abundance values between the exploited and protected sites of Amathole (Fig. 6a). The univariate (pseudo- $F_{1}=0.61 ; \mathrm{p}=0.501$ ) and SIMPER analyses supported this pattern, and the highest contributing species reacted differently to protection (Fig. 6e). In contrast to the abundances of the target species, higher biomass of target species were observed inside the Amathole MPA (Fig. 6b). This result was further supported by the univariate (mean $\pm \mathrm{SD}$; protected: $260.4 \pm 270.1 \mathrm{~g}$, exploited: $66.9 \pm 44.3 \mathrm{~g}$, pseudo- $\left.F_{1}=19.8 ; \mathrm{p}=0.009\right)$ and SIMPER analyses (Fig. 6f). Generally, low abundance and biomass values were recorded for the non-target species of the Amathole MPA. The non-target fish assemblage composition differed between the Amathole MPA and adjacent fished sites, and according to the mMDS and SIMPER results, higher abundances were recorded outside the Amathole MPA (Fig. 6c,e). However, this pattern of greater abundances of non- target species outside the Amathole MPA was not supported by the univariate analysis (pseudo- $F_{1}=$ $3.2 ; \mathrm{p}=0.103)$. No difference in the multivariate analysis of the non-target biomass data were observed (Fig. 6d), a result which was supported by the univariate analysis (pseudo- $F_{1}=0.79 ; \mathrm{p}=0.495$ ).

\subsubsection{Pondoland Marine Protected Area}

Multivariate analyses of the Pondoland fish assemblages revealed that protection significantly changed the abundance and biomass of the target species, and the abundances (but not biomass) of the non-target species (Fig. 7a-c). Although protection significantly affected the assemblage structure of the target species abundances, no clear trend was observed for this group, and the mMDS and the SIMPER analyses suggest similar abundances inside and outside the Pondoland MPA. This result was supported by the univariate analysis (pseudo- $F_{1}=2.36 ; \mathrm{p}=0.169$ ). In contrast, the mMDS, SIMPER and univariate results all revealed higher biomass values of target species inside the Pondoland MPA (mean $\pm \mathrm{SD}$; protected: $286.1 \pm 193.9 \mathrm{~g}$, exploited: $97.9 \pm 50.2 \mathrm{~g}$, pseudo- $F_{1}=$ $14.93 ; \mathrm{p}=0.017$; Fig. $7 \mathrm{~b}, \mathrm{f})$. The analysis of the nontarget species assemblages indicated that they occurred at higher abundances outside the MPA (protected: $3.4 \pm 3.2$, exploited: $6.2 \pm 5$, pseudo- $F_{1}=11.18$; $\mathrm{p}=0.029$; Fig. $7 \mathrm{c}, \mathrm{e}$ ). This pattern was not reflected in the non-target biomass analyses, where no clear trend was evident (pseudo- $F_{1}=2.5 ; \mathrm{p}=0.177$; Fig. 7d,f).

\section{DISCUSSION}

The aim of this study was to investigate direct and indirect effects of protection on reef fish at the community level in an attempt to better understand MPA effectiveness. In theory, indirect effects (i.e. those stemming from a knock-on effect initiated by target fish recovery) can only be assumed if direct effects have been detected. Here, significantly higher biomass or greater abundance of sexually mature target species inside MPAs in combination with a reduced abundance of non-target species inside MPAs was considered a clear positive reserve effect at the community level. Based on the traitbased analyses, the general pattern is that the 5 South African MPAs have had community-wide impacts on reef fishes, which suggests that the MPAs are effective. However, closer inspection of 
Bird Island Marine Protected Area (Algoa Bay)

a) Target species (abundance)

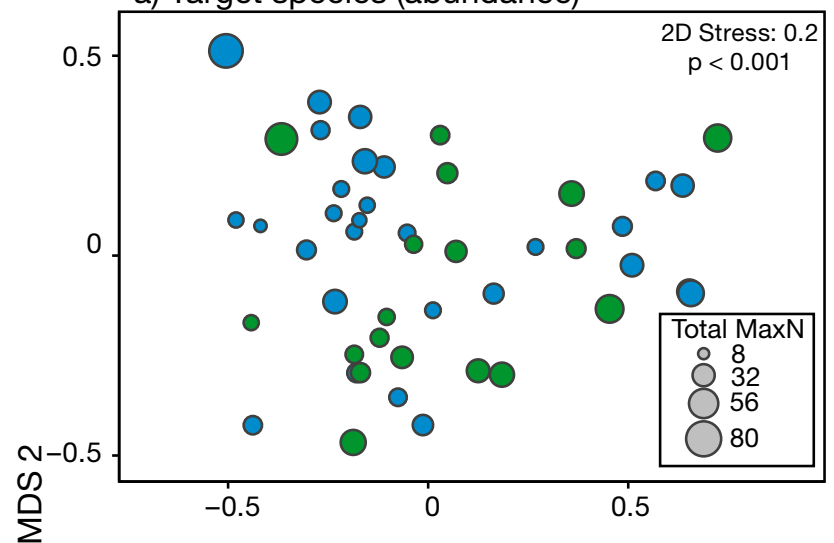

c) Non-target species (abundance)

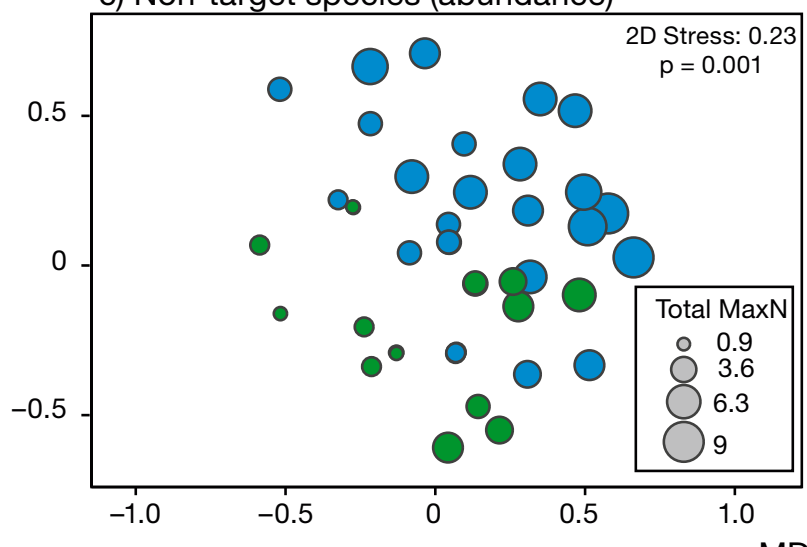

b) Target species (biomass)

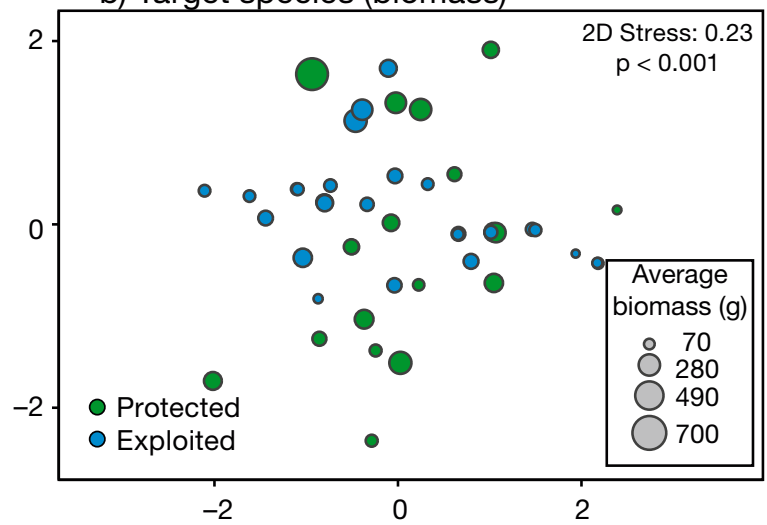

d) Non-target species (biomass)

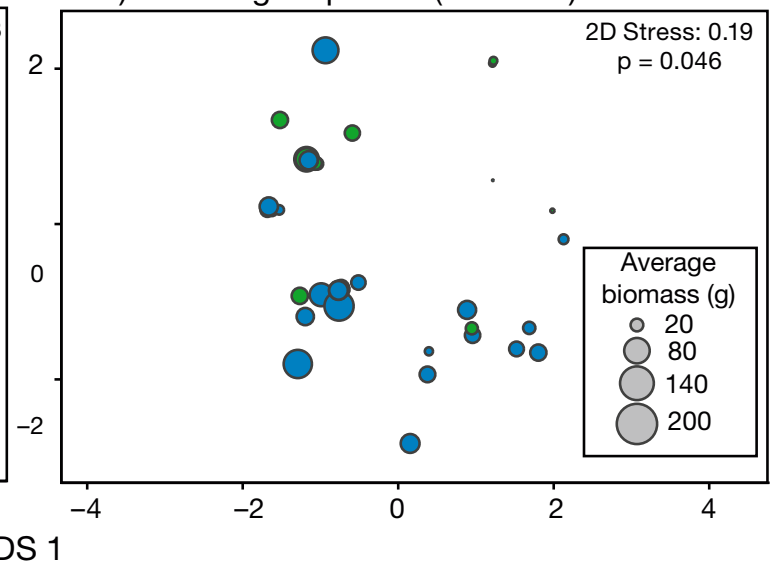

e) SIMPER: abundance

f) SIMPER: biomass

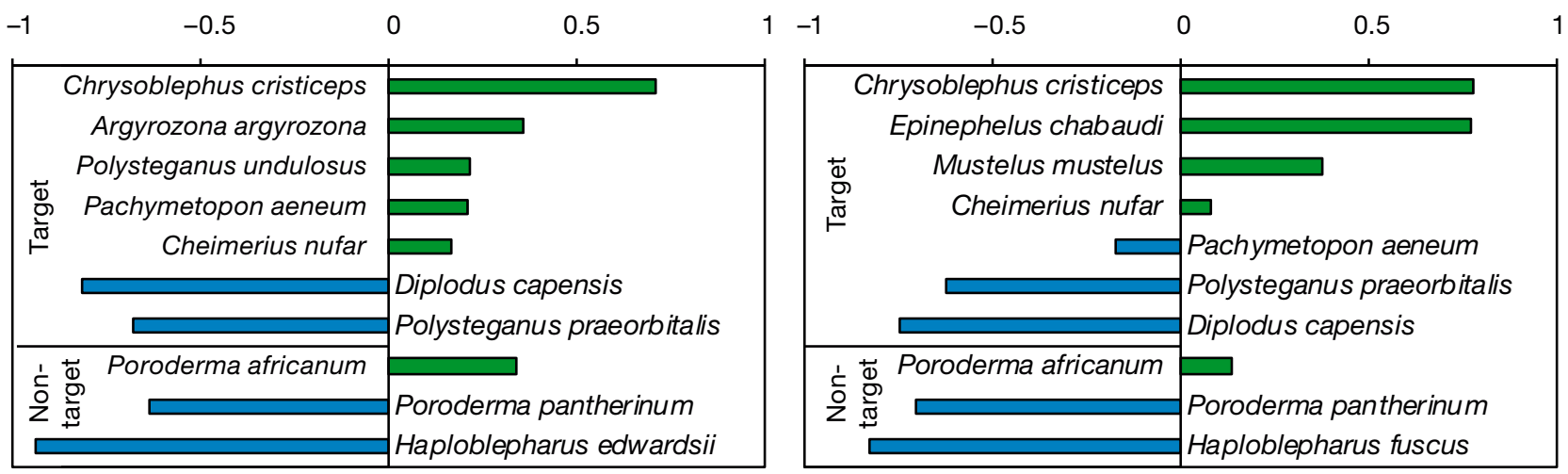

Relative difference

Fig. 5. As in Fig. 3, but for the Bird Island Marine Protected Area

the multivariate species data indicates that despite a significant difference in the fish assemblages between protected and exploited sites at most locations, the direction of change was not consistent, and only 3 of the MPAs show clear positive reserve effects at the community level.

\subsection{Trait-based analyses}

It seems that accounting for traits at the individual level (ISFEs) is especially important for the detection of the direct effects of protection. Here, we incorporated the size of fish as an individual trait, since it 


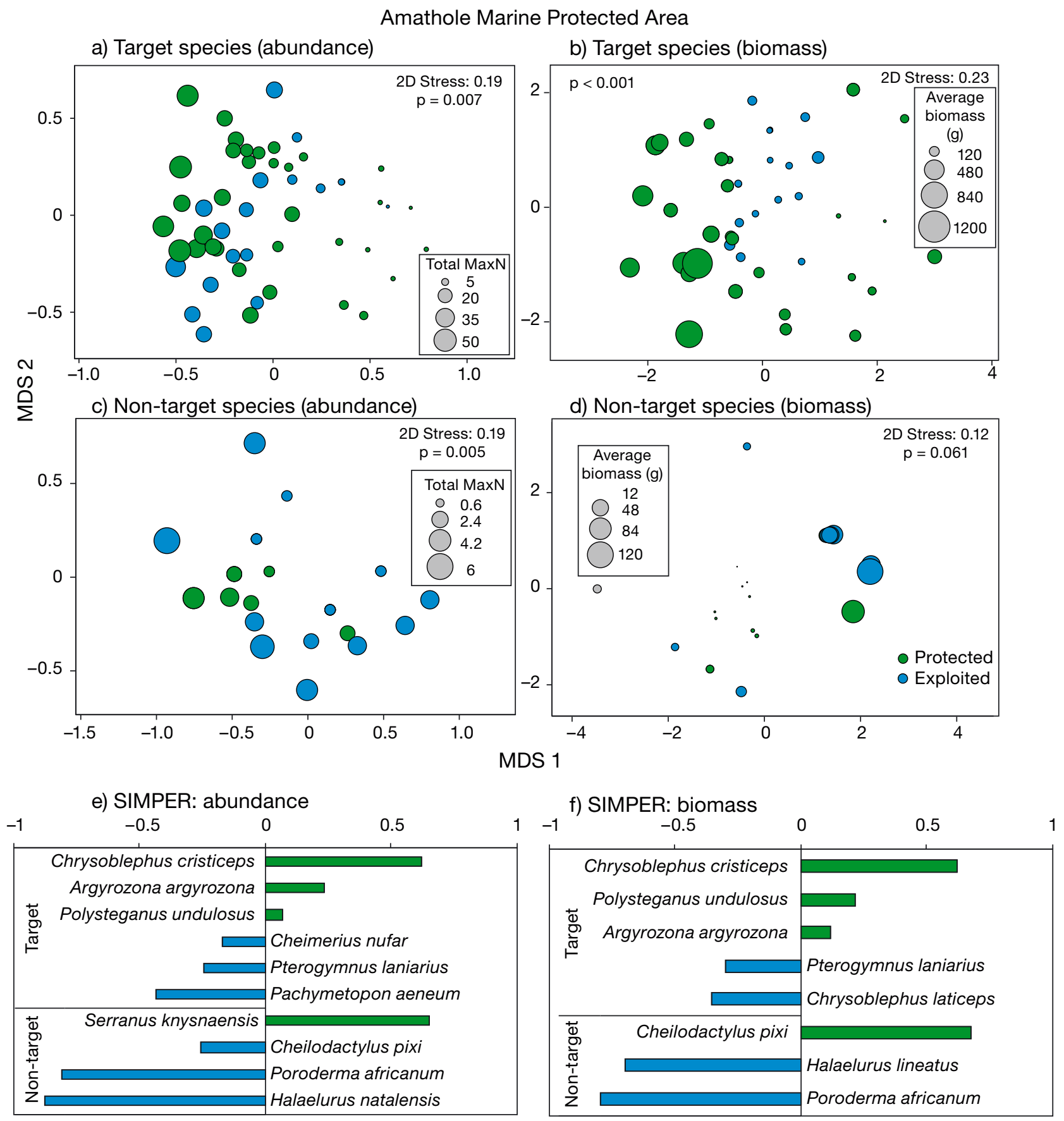

Relative difference

Fig. 6. As in Fig. 3, but for the Amathole Marine Protected Area

changes with age, correlates with life history parameters (Blueweiss et al. 1978), is important in species interactions (Cohen et al. 1993), and is essential when considering fishing effects (Rochet \& Trenkel 2003, Graham et al. 2005). Ignoring important changes in function that occur throughout ontogeny results in an inadequate description of a fish community (Rudolf \& Rasmussen 2013, Mindel et al. 2016), as is evident in the target SFEs analyses presented here. Protection mostly affected the age structure of the functional entities within the target group (demonstrated in the analysis of the ISFEs) and the 


\section{Pondoland Marine Protected Area}

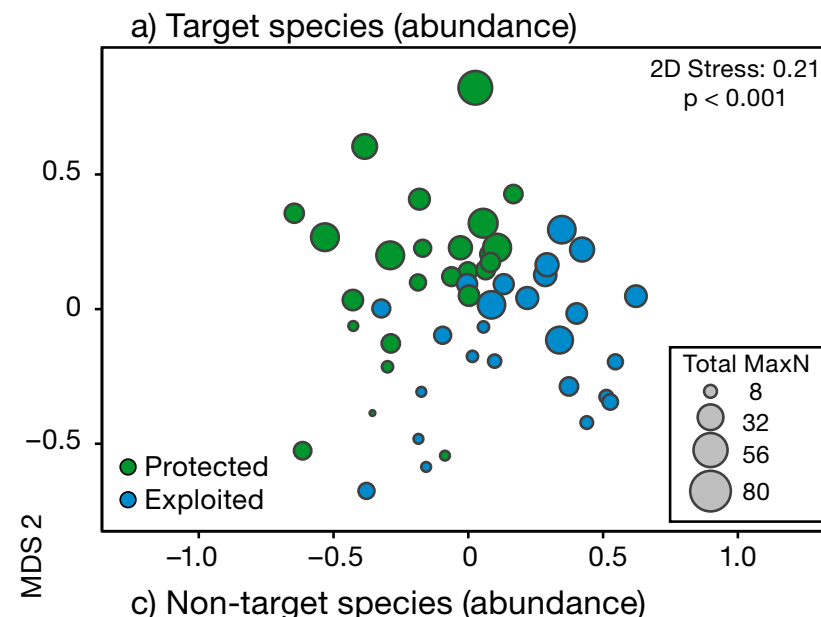

c) Non-target species (abundance)

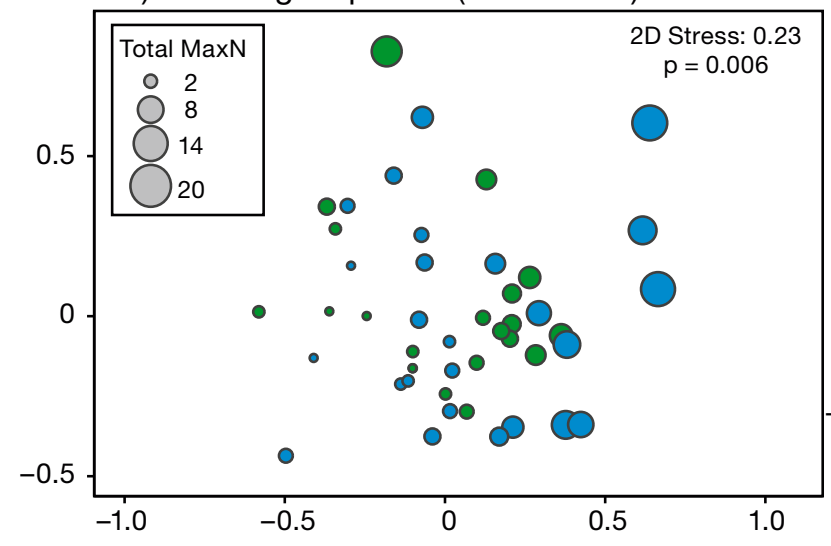

b) Target species (biomass)

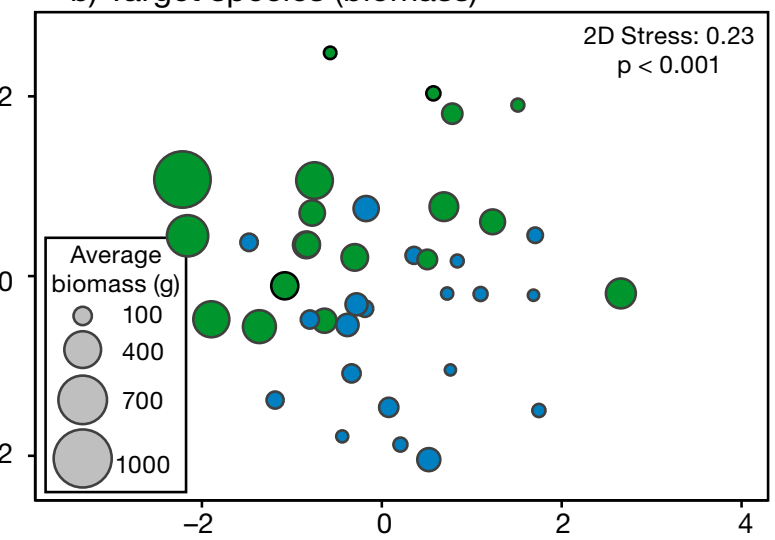

d) Non-target species (biomass)

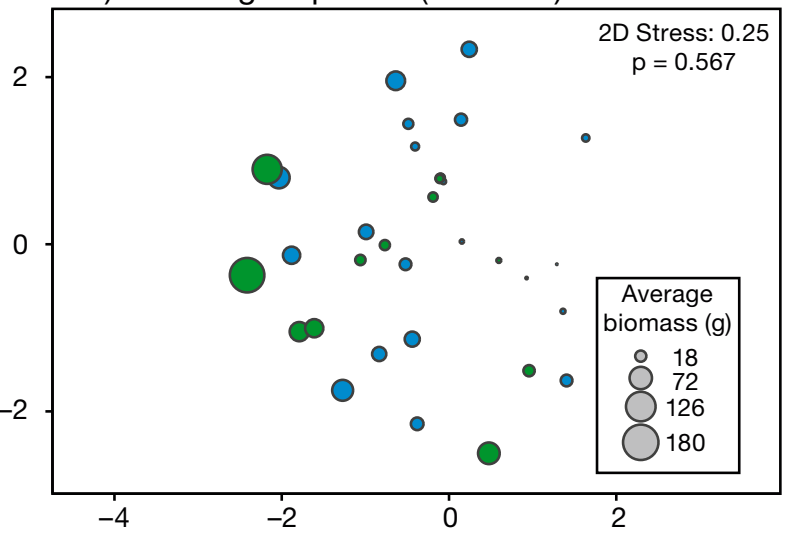

MDS 1

e) SIMPER: abundance

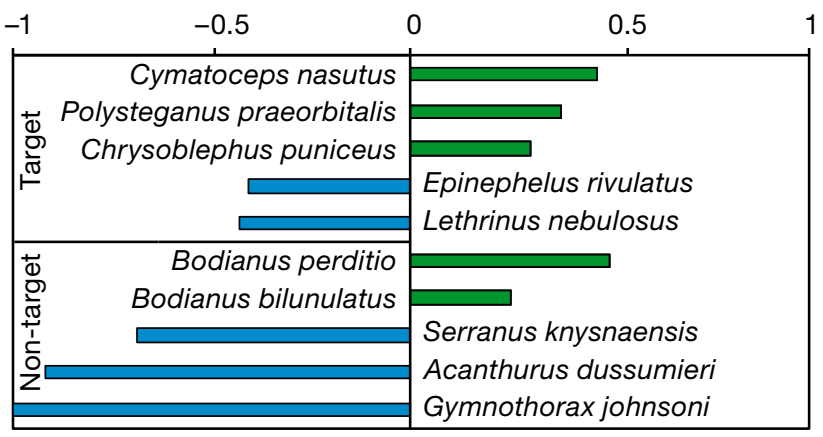

f) SIMPER: biomass

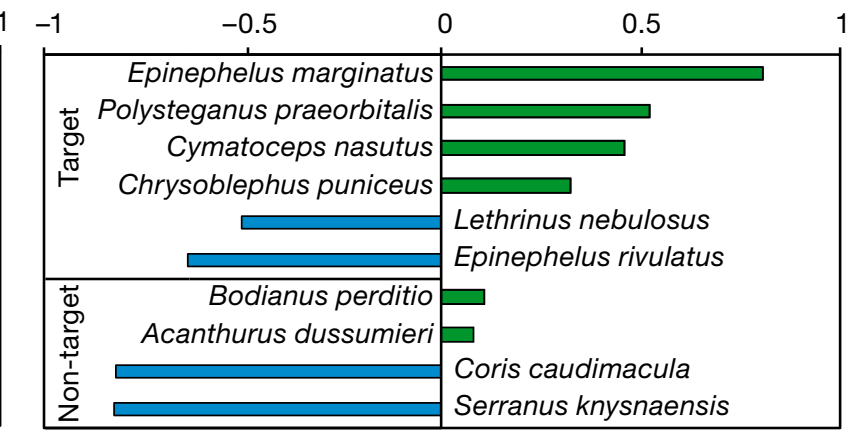

Relative difference

Fig. 7. As in Fig. 3, but for the Pondoland Marine Protected Area

abundance of functional entities in the non-target groups (demonstrated in the analysis SFEs; Tables S4 \& S5). Here, protection increased the abundance of adult target species and decreased the abundance of non-target species inside MPAs (Fig. 2b,c) suggesting a positive overall reserve effect, and that the 5
South African MPAs investigated here are generally successful.

The positive reserve effect appeared to be strongest for the adult life-stage of large $(60-120 \mathrm{~cm})$, general carnivore, bentho-pelagic species that typically move within reef complexes and occur in small 
groups (Fig. 2c). This implies that, in the geographical context of this research, these types of species benefit most from protection, and are potentially the most vulnerable to fishing impacts. Interestingly, the opposite was true for juveniles of this functional group, which were more abundant outside the MPAs, and might suggest that the presence of adults may influence the recruitment, survival or detectability of juveniles.

\subsection{Location-specific analyses based on species assemblages}

While 'status' had a significant effect in the full analysis, the location-specific analysis showed that not all of the MPAs are fulfilling their ecological potential (Table 2). Three of the MPAs (Tsitsikamma, Bird Island and Pondoland) clearly demonstrated both direct and indirect effects of protection (Table 2), suggesting that the fish assemblages within these MPAs may have returned towards some previous state prior to intense exploitation (Babcock et al. 2010). The Amathole MPA demonstrated clear direct effects, but the indirect effects were not recorded in all analyses. On the other hand, no direct effects were recorded in the De Hoop MPA, and indirect effects were only evident in the multivariate response data; it is unlikely that these were related to the presence of the MPA (Table 2).

Within the Agulhas ecoregion (see Fig. 1), the recovery of target species (e.g. Chrysoblephus laticeps, C. cristiceps, Argyrozona argyrozona) appeared to indirectly effect non-target species primarily from the Scyliorhinidae family (e.g. Poroderma africanum, $P$. pantherium). These non-target species occupy a similar trophic position to the target species, and would not be considered their prey (Mann 2013). As such, the indirect effects identified in this research are likely driven by competition rather than predation. Many of the Scyliorhinidae species are nocturnally active (Mann 2013), and it is possible that higher abundances of large competitors inside MPAs promotes nocturnal activity, while the lack of competition outside MPAs allows them to be more active during daytime. In the Pondoland MPA, which is situated in the sub-tropical ecoregion of southern Africa, species within the target group that showed a strong recovery, included both potential predators (Epinephelus marginatus and Polysteganus praeorbitalis) and competitors (Cymatoceps nasutus and Chrysoblephus puniceus) of the non-target species, suggesting that multiple factors may be driving the indirect effects detected here.

In a recent study, Edgar et al. (2014) showed that the ecological conservation benefits associated with MPAs were highly dependent on the degree to which fishing is allowed within MPAs; level of enforcement; MPA age; MPA size and degree of ecological isolation (habitat disruption inhibiting movement of fish across MPA boundaries). Accumulation of these 5 key features, namely that a MPA is considered notake, enforced, old, large and isolated (NEOLI), exponentially increased the positive ecological response to protection (Edgar et al. 2014). Here we summarise the main findings of the analyses for each

Table 2. Summary of the location-specific results. Locations were ranked according to the NEOLI criteria (abbreviations as in Table 1; see Edgar et al. 2014), with Tsitsikamma scoring the highest and Bird Island the lowest (see Table 1 for the classification of each location). Values in bold represent a significant effect

\begin{tabular}{|c|c|c|c|c|c|c|c|c|}
\hline \multirow{2}{*}{ MPA } & \multirow{2}{*}{ Measure } & \multirow{2}{*}{$\begin{array}{l}\text { Fisheries } \\
\text { group }\end{array}$} & \multirow{2}{*}{$\begin{array}{l}\text { Multi- } \\
\text { variate }\end{array}$} & \multicolumn{2}{|c|}{ Overall trend } & \multirow{2}{*}{$\begin{array}{c}\text { Uni- } \\
\text { variate }\end{array}$} & \multicolumn{2}{|c|}{ Abundance or biomass (mean $\pm \mathrm{SD})$} \\
\hline & & & & Bubbles & SIMPER & & Protected & Exploited \\
\hline \multirow{2}{*}{$\begin{array}{l}\text { Tsitsikamma } \\
\text { (NEOL) }\end{array}$} & a Biomass & Target & $<0.001$ & Higher inside & Higher inside & 0.003 & $175.2 \pm 153.6$ & $36.6 \pm 40.4$ \\
\hline & Abundance & Non-target & $<0.001$ & No clear pattern & Higher outside & $<0.001$ & $2.9 \pm 2.1$ & $4.7 \pm 3.1$ \\
\hline \multirow{2}{*}{$\begin{array}{l}\text { De Hoop } \\
\text { (NOLI) }\end{array}$} & Biomass & Target & $<0.001$ & Higher outside & Higher outside & 0.337 & $72.1 \pm 71.8$ & $130.5 \pm 156$ \\
\hline & Abundance & Non-target & $<0.001$ & Higher outside & Higher outside & 0.091 & $1.9 \pm 2.3$ & $5.85 \pm 2.8$ \\
\hline \multirow{2}{*}{$\begin{array}{l}\text { Pondoland } \\
\text { (NELI) }\end{array}$} & Biomass & Target & $<0.001$ & Higher inside & Higher inside & 0.018 & $286.1 \pm 193.9$ & $97.9 \pm 50.2$ \\
\hline & Abundance & Non-target & 0.0061 & Higher outside & Higher outside & 0.028 & $3.4 \pm 3.2$ & $6.2 \pm 5$ \\
\hline \multirow{2}{*}{$\begin{array}{l}\text { Amathole } \\
(\mathrm{NOL})\end{array}$} & Biomass & Target & $<0.001$ & Higher inside & Higher inside & 0.009 & $260.4 \pm 270.1$ & $66.9 \pm 44.3$ \\
\hline & Abundance & Non-target & 0.005 & Higher outside & Higher outside & 0.103 & $0.8 \pm 1.2$ & $2.0 \pm 1.7$ \\
\hline \multirow{2}{*}{$\begin{array}{l}\text { Bird Island } \\
\text { (NI) }\end{array}$} & Biomass & Target & $<0.001$ & Higher inside & Higher inside for & 0.021 & $195.6 \pm 127.6$ & $121.1 \pm 57.5$ \\
\hline & Abundance & Non-target & 0.001 & Higher outside & Higher outside & 0.014 & $2.6 \pm 1.7$ & $4.3 \pm 2.5$ \\
\hline
\end{tabular}


MPA, with the MPAs arranged according to their theoretical effectiveness derived from the NEOLI criteria (Table 2). Three of the MPAs investigated here (Tsitsikamma, De Hoop and Pondoland) scored 4 out of the 5 NEOLI features (Table S12). While the results from Pondoland and Tsitsikamma conform to the level of effectiveness predicted by Edgar et al. (2014), De Hoop did not demonstrate a reserve effect, and abundance and biomass of target species tended to be higher outside, rather than inside the MPA (Fig. 3).

The lack of reserve effect at De Hoop is most likely due to the absence of suitable offshore habitat for reef fish species (Table 1). According to a recent mapping report (Coetzee et al. 2017), reef habitat was almost non-existent within the De Hoop MPA, with most of the habitat classified as reef restricted to the shoreline. Indeed, previous research has demonstrated that the De Hoop MPA has had a positive effect on the fish communities that occupy the reefs of this narrow coastal belt (Bennett \& Attwood 1991). Outside the MPA there are large expanses of offshore reef that support important hook and line fisheries. In the analyses we controlled for habitat by excluding samples collected on sand and including bottom type as a random effect. Consequently, the absence of a reserve effect at De Hoop suggests that the observed results are not due to sample-specific habitat differences, but could rather be related to the area of available habitat at the reserve level. Several studies have shown that predator biomass scales with habitat size, and larger habitats (reefs) support higher biomass of predatory and larger fish species (Bohnsack et al. 1994, McIntosh et al. 2018). Therefore, despite the increased vulnerability of target species outside the reserve, access to more suitable habitat plays a more important role than fishing in structuring fish populations. While the De Hoop MPA may provide little benefit to offshore reef fish, the protection of sand habitat may benefit other target fish species (e.g. the sand associated Mustelus mustelus; Fig. 3e,f), and gives further support to the predominance of sand habitat in this reserve. Ensuring that an adequate quantity of the correct habitat is afforded protection within MPAs is an essential planning feature prior to MPA establishment (Foley et al. 2010). The concept of essential fish habitat (Rosenberg et al. 2000) is crucial in an ecosystem approach to fisheries management, as protecting the correct habitat ensures fisheries and conservation benefits, thereby avoiding the establishment of 'paper parks' (Edgar 2017).

High scoring MPAs (those with at least 4 out of 5 features) were most effective according to Edgar et al. (2014). For the most part, our results provide sup- port for the NEOLI criteria in predicting MPA effectiveness, with Tsitsikamma and Pondoland (scoring 4 out of 5 NEOLI features; Table S12 \& S13) demonstrating strong positive reserve effects at the resource (target fish species) and community level (Table 2). Established in 1964, Tsitsikamma is an old no-take MPA and the only NEOLI feature it was lacking is isolation, as there is a degree of connectivity between the coastal reefs in the region (Table S12). Pondoland, is relatively young (10 yr old when the data were collected), but it has a very large no-take zone and is situated in a relatively inaccessible region with low population densities and limited access to the offshore marine environment.

Isolation was considered by both Edgar et al. (2014) and the follow-up analysis by Rudd (2015), to disproportionately improve the positive ecological response to protection, and demonstrated the strongest influence on richness and biomass. The importance of this NEOLI category seems to further explain the success of the relatively young Pondoland MPA (Maggs et al. 2013) and the small and young Bird Island MPA, which only scored 2 of the 5 NEOLI criteria (no-take and isolation; Tables 1, S12 \& S13). Bird Island is an offshore MPA consisting predominantly of reef which is isolated from the mainland and adjacent reefs by expanses of sand habitat. The island is also home to large colonies of sea birds and seals, and is likely to be a highly productive ecosystem (Chadwick et al. 2014). It is possible that isolation, together with suitable habitat and high productivity combine to enhance the effectiveness of this small MPA. The proposed inclusion of the Bird Island into the substantially larger Addo MPA (Government Gazette No. 39646) will likely further enhance the value of this protected area.

Indirect effects were apparent in the Amathole MPA, but unlike those seen in Pondoland, Bird Island and Tsitsikamma (which demonstrated indirect effects in the multivariate response and the total abundance data), the total abundance of non-target species in the Amathole MPA was not significantly affected (Table 2). The high connectivity (or lack of isolation) of reef habitat inside and outside of the Amathole MPA may explain the absence of clear indirect effects at this site. The Amathole MPA is characterised by 3 of the 5 NEOLI criteria (no-take, old and large). While the MPA is large, it consists of 3 no-take zones (areas: 62, 61 and $123 \mathrm{~km}^{2}$ ) that are separated by approximately $20 \mathrm{~km}$ of coastline where intense fishing occurs. The reef habitat within the no-take zones is patchy, and where there are notable reef complexes, these straddle the MPA 
boundaries. It is possible that the limited habitat and high degree of connectivity between protected and exploited habitats have precluded the emergence of strong indirect effects on the assemblage of non-target species. More informed spatial planning is thus required for the establishment of no-take areas in the recently proposed extension of the Amathole MPA (Government Gazette No. 39646).

The results of the present study suggest that it may be inappropriate to consider only species-level functional traits when attempting to assess the direct effects of protection. The size of individual fish is non-randomly influenced by fishers, and plays an important role in both population and community ecology. Our results highlight the value of including size to capture a portion of the individual-level variation within functional trait-based analyses that aim to investigate fishing effects. Furthermore, many, if not most, species-level functional traits (e.g. diet, habitat and depth preferences) change according to the age and size of the fish, and this should be incorporated within the classification of functional entities. The positive ecological response at the resource level for most of the South African MPAs examined indicates that no-take MPAs support greater biomass of target species within their boundaries. Indirect effects are evident as the emergent effects on non-target species populations when large individuals of species targeted by fisheries are present or increase in abundance. However, indirect effects were not consistently recorded at all locations, and it is possible that this can be attributed to shortcomings in individual MPA design. While the NEOLI criteria are useful predictors of MPA effectiveness, our results demonstrate the importance of not only protecting the correct habitat, but also including adequate quantities of suitable habitat when designing MPAs. Further research should be directed into measuring the effect of habitat area, at the landscape or reserve level, on reef ecosystem productivity and MPA effectiveness.

Acknowledgements. Funding for this project was provided by the National Research Foundation of South Africa and the British Ecological Society. We thank SANParks, CapeNature, Eastern Cape Parks and Tourism Agency for allowing us to sample in their MPAs and everyone that helped in the field and lab. Finally, we thank Professor Marti Anderson for her guidance and input with the statistical analyses.

\section{LITERATURE CITED}

Aburto-Oropeza O, Erisman B, Galland GR, MascareñasOsorio I, Sala E, Ezcurra E (2011) Large recovery of fish biomass in a no-take marine reserve. PLOS ONE 6(8): e23601
Agardy T, Bridgewater P, Crosby MP, Day J and others (2003) Dangerous targets? Unresolved issues and ideological clashes around marine protected areas. Aquat Conserv 13:353-367

Anderson MJ, Diebel CE, Blom WM, Landers TJ (2005) Consistency and variation in kelp holdfast assemblages: spatial patterns of biodiversity for the major phyla at different taxonomic resolutions. J Exp Mar Biol Ecol 320: 35-56

Anderson MJ, Ellingsen KE, McArdle BH (2006) Multivariate dispersion as a measure of beta diversity. Ecol Lett 9: 683-693

Anderson MJ, Gorley RN, Clarke KR (2008) PERMANOVA+ for PRIMER: guide to software and statistical methods. PRIMER-E, Plymouth

Babcock RC, Kelly S, Shears NT, Walker JW, Willis TJ (1999) Changes in community structure in temperate marine reserves. Mar Ecol Prog Ser 189:125-134

Babcock RC, Shears NT, Alcala AC, Barrett NS and others (2010) Decadal trends in marine reserves reveal differential rates of change in direct and indirect effects. Proc Natl Acad Sci USA 107:18256-18261

Bennett B, Attwood C (1991) Evidence for recovery of a surfzone fish assemblage following the establishment of a marine reserve on the southern coast of South Africa. Mar Ecol Prog Ser 75:173-181

* Bernard A, Götz A, Parker D, Heyns E and others (2014) New possibilities for research on reef fish across the continental shelf of South Africa. S Afr J Sci 110:1-5

* Blueweiss L, Fox H, Kudzma D, Nakashima D, Peters R, Sams S (1978) Relationships between body size and some life history parameters. Oecologia 37:257-272

Bohnsack JA, Harper DE, Mcclellan DB, Hulsbeck M (1994) Effects of reef size on colonization and assemblage structure of fishes at artificial reef off southeastern Florida, USA. Bull Mar Sci 55:796-823

Chadwick P, Duncan J, Tunley K (2014) State of management of South Africa's marine protected areas. WWF South Africa Report Series 2014/Marine/001, WWF-SA, Capetown

Chase JM, Abrams PA, Grover JP, Diehl S and others (2002) The interaction between predation and competition: a review and synthesis. Ecol Lett 5:302-315

Clarke KR, Gorley RN (2015) PRIMER v7: user manual/ tutorial, 1st edn. PRIMER-E, Plymouth

Coetzee J, Merkle D, Rademan J, Erasmus C (2017) Report on de Hoop bathymetry survey - August 2017 Department of Agriculture, Forestry and Fisheries, Cape Town

Cohen JE, Pimm SL, Yodzis P, Saldana J (1993) Body sizes of animal predators and animal prey in food webs. J Anim Ecol 62:67-78

Coleman MA, Bates AE, Stuart-Smith RD, Malcolm HA and others (2015) Functional traits reveal early responses in marine reserves following protection from fishing. Divers Distrib 21:876-887

Cowley P, Brouwer S, Tilney R (2002) The role of the Tsitsikamma National Park in the management of four shore-angling fish along the south-eastern Cape coast of South Africa. S Afr J Mar Sci 24:27-35

Day JC, Roff JC (2000) Planning for representative marine protected areas: a framework for Canada's oceans. Report prepared for World Wildlife Fund Canada, Toronto

Edgar GJ (2017) Marine protected areas need accountability not wasted dollars. Aquat Conserv 27:4-9

* Edgar GJ, Stuart-Smith RD, Willis T, Kininmonth S and oth- 
ers (2014) Global conservation outcomes depend on marine protected areas with five key features. Nature 506: 216-220

Fletcher WJ, Shaw J, Metcalf SJ, Gaughan DJ (2010) An ecosystem based fisheries management framework: the efficient, regional-level planning tool for management agencies. Mar Policy 34:1226-1238

Foley MM, Halpern BS, Micheli F, Armsby MH and others (2010) Guiding ecological principles for marine spatial planning. Mar Policy 34:955-966

Froese R, Pauly D (2014) FishBase. www.fishbase.org

* Gell FR, Roberts CM (2003) Benefits beyond boundaries: the fishery effects of marine reserves. Trends Ecol Evol 18: 448-455

Gill DA, Mascia MB, Ahmadia GN, Glew L and others (2017) Capacity shortfalls hinder the performance of marine protected areas globally. Nature 543:665-669

Götz A, Kerwath S, Attwood CG, Sauer WHH (2009) Effects of fishing on a temperate reef community in South Africa. I. Ichthyofauna. Afr J Mar Sci 31:241-251

Graham N, Dulvy NK, Jennings S, Polunin N (2005) Sizespectra as indicators of the effects of fishing on coral reef fish assemblages. Coral Reefs 24:118-124

G Gwinn DC, Allen MS, Johnston FD, Brown P, Todd CR, Arlinghaus R (2015) Rethinking length-based fisheries regulations: the value of protecting old and large fish with harvest slots. Fish Fish 16:259-281

*Halpern BS (2003) The impact of marine reserves: do reserves work and does reserve size matter? Ecol Appl 13:117-137

Halpern BS (2014) Making marine protected areas work. Nature 506:167-168

Harvey ES, Shortis M (1996) A system for stereo-video measurement of sub-tidal organisms. Mar Technol Soc J 29:10-27

Harvey ES, Shortis MR (1998) Calibration stability of an underwater stereo-video system: implications for measurement accuracy and precision. Mar Technol Soc J 32: 3-17

Harvey ES, Fletcher D, Shortis M (2001) Improving the statistical power of length estimates of reef fish: a comparison of estimates determined visually by divers with estimates produced by a stereo-video system. Fish Bull 99:72-80

Hedley J (2003) Vidana 1.0: video analysis for cover estimation. https://drive.google.com/file/d/12_Me8obE3qhUz pqoOdaGpsmp9Zosd633/view

* Hilborn R, Stokes K, Maguire JJ, Smith T and others (2004) When can marine reserves improve fisheries management? Ocean Coast Manage 47:197-205

*Hockey PAR, Branch GM (1997) Criteria, objectives and methodology for evaluating marine protected areas in South Africa. S Afr J Mar Sci 18:369-383

Jennings S, Kaiser MJ (1998) The effects of fishing on marine ecosystems. Adv Mar Biol 34:201-352

* Jennings S, Greenstreet SPR, Reynolds JD (1999) Structural change in an exploited fish community: a consequence of differential fishing effects on species with contrasting life histories. J Anim Ecol 68:617-627

Jones PJS (2007) Point-of-view. Arguments for conventional fisheries management and against no-take marine protected areas: only half of the story? Rev Fish Biol Fish 17: 31-43

Keddy PA (1992) Assembly and response rules: two goals for predictive community ecology. J Veg Sci 3:157-164

Lamanna C, Blonder B, Violle C, Kraft NJB and others (2014)
Functional trait space and the latitudinal diversity gradient. Proc Natl Acad Sci USA 111:13745-13750

* Langlois T, Fitzpatrick BM, Fairclough DV, Wakefield CB and others (2012a) Similarities between line fishing and baited stereo-video estimations of length-frequency: novel application of Kernel Density Estimates. PLOS ONE 7:e45973

* Langlois T, Harvey ES, Meeuwig JJ (2012b) Strong direct and inconsistent indirect effects of fishing found using stereo-video: testing indicators from fisheries closures. Ecol Indic 23:524-534

Lester SE, Halpern BS, Grorud-Colvert K, Lubchenco J and others (2009) Biological effects within no-take marine reserves: a global synthesis. Mar Ecol Prog Ser 384:33-46

*Maggs JQ, Mann BQ, Cowley PD (2013) Contribution of a large no-take zone to the management of vulnerable reef fishes in the South-West Indian Ocean. Fish Res 144: $38-47$

Mann BQ (ed) (2013) Southern African marine linefish species profiles. Special Publication 9, Oceanographic Research Institute, Durban

* McIntosh AR, McHugh PA, Plank MJ, Jellyman PG, Warburton HJ, Greig HS (2018) Capacity to support predators scales with habitat size. Sci Adv 4:eaap7523

* Micheli F, Halpern B, Botsford L, Warner R (2004) Trajectories and correlates of community change in no-take marine reserves. Ecol Appl 14:1709-1723

*Miller KI, Russ GR (2014) Studies of no-take marine reserves: methods for differentiating reserve and habitat effects. Ocean Coast Manage 96:51-60

*Mindel BL, Webb TJ, Neat FC, Blanchard JL (2016) A traitbased metric sheds new light on the nature of the body size-depth relationship in the deep sea. J Anim Ecol 85: 427-436

*Mouillot D, Graham NAJ, Villéger S, Mason NWH, Bellwood DR (2013) A functional approach reveals community responses to disturbances. Trends Ecol Evol 28: $167-177$

Mouillot D, Villéger S, Parravicini V, Kulbicki M and others (2014) Functional over-redundancy and high functional vulnerability in global fish faunas on tropical reefs. Proc Natl Acad Sci USA 111:13757-13762

*Myers RA, Worm B (2003) Rapid worldwide depletion of predatory fish communities. Nature 423:280-283

* Pauly D, Christensen V, Guenette S, Pitcher TJ and others (2002) Towards sustainability in world fisheries. Nature 418:689-695

* Pikitch E, Santora C, Babcock E, Bakun A and others (2004) Ecosystem-based fishery management. Science 305: 346-347

*Pinnegar JK, Polunin NVC, Francour P, Badalamenti F and others (2000) Trophic cascades in benthic marine ecosystems: lessons for fisheries and protected-area management. Environ Conserv 27:179-200

* Rice J, Moksness E, Attwood C, Brown SK and others (2012) The role of MPAs in reconciling fisheries management with conservation of biological diversity. Ocean Coast Manage 69:217-230

Kochet M, Trenkel VM (2003) Which community indicators can measure the impact of fishing? A review and proposals. Can J Fish Aquat Sci 60:86-99

Rosenberg A, Bigford TE, Leathery S, Hill RL, Bickers K (2000) Ecosystem approaches to fishery management through essential fish habitat. Bull Mar Sci 66:535-542

Rudd MA (2015) Pathways from marine protected area 
design and management to ecological success. PeerJ 3: e1424

Rudolf VHW, Rasmussen NL (2013) Population structure determines functional differences among species and ecosystem processes. Nat Commun 4:2318

Russ GR, Alcala AC (2003) Marine reserves: rates and patterns of recovery and decline of predatory fish, 1983-2000. Ecol Appl 13:1553-1565

Salomon AK, Gaichas SK, Shears NT, Smith JE, Madin EMP, Gaines SD (2010) Key features and context-dependence of fishery-induced trophic cascades. Conserv Biol 24: 382-394

Sink K, Holness S, Harris L, Majiedt P and others (2012) National Biodiversity Assessment 2011: Technical Report, Vol 4. Marine and coastal component. South African National Biodiversity Institute, Pretoria

Soler GA, Edgar GJ, Thomson RJ, Kininmonth S and others (2015) Reef fishes at all trophic levels respond positively to effective marine protected areas. PLOS ONE 10: $\mathrm{e} 0140270$

Spalding MD, Fox HE, Allen GR, Davidson N and others (2007) Marine ecoregions of the world: a bioregionalization of coastal and shelf areas. BioScience 57: 573-583

Taylor MD, Baker J, Suthers IM (2013) Tidal currents, sampling effort and baited remote underwater video (BRUV) surveys: Are we drawing the right conclusions? Fish Res 140:96-104

Editorial responsibility: Stephen Wing,

Dunedin, New Zealand
Thrush SF, Dayton PK (2010) What can ecology contribute to ecosystem-based management? Annu Rev Mar Sci 2: 419-441

*Villéger S, Brosse S, Mouchet M, Mouillot D, Vanni MJ (2017) Functional ecology of fish: current approaches and future challenges. Aquat Sci 79:783-801

* Violle C, Reich PB, Pacala SW, Enquist BJ, Kattge J (2014) The emergence and promise of functional biogeography. Proc Natl Acad Sci USA 111:13690-13696

*Watson D, Harvey ES, Anderson MJ, Kendrick G (2005) A comparison of temperate reef fish assemblages recorded by three underwater stereo-video techniques. Mar Biol 148:415-425

Weiher E, Keddy PA (1995) Assembly rules, null models, and trait dispersion: new questions from old patterns. Oikos 74:159-164

Willis T, Babcock R (2000) A baited underwater video system for the determination of relative density of carnivorous reef fish. Mar Freshw Res 51:755-763

* Willis TJ, Millar RB (2005) Using marine reserves to estimate fishing mortality. Ecol Lett 8:47-52

* Woodcock P, Leary BCO, Kaiser MJ, Pullin AS (2017) Your evidence or mine? Systematic evaluation of reviews of marine protected area effectiveness. Fish Fish 18: $668-681$

Worm B, Barbier EB, Beaumont N, Duffy JE and others (2006) Impacts of biodiversity loss on ocean ecosystem services. Science 314:787-790

Submitted: October 26, 2018; Accepted: April 17, 2019

Proofs received from author(s): May 24, 2019 